\title{
Children and young people around
} the UK

\author{
By James Bayliss and Frances Sly', Office for National Statistics
}

\section{Abstract}

The well-being of children and young people in the UK has become an increasing concern of local and national government in recent times. This article explores regional and sub-regional geographic variations in a number of themes relating to this key population sub-group, such as educational attainment from early years to age 19 , participation in education and training at ages 16 and 17 , aspects of health and local authority care, and court sentencing of juveniles committing crimes.

Statistics at regional level often highlight disparities between southern regions of England (apart from London) and those in the north. This is clearly seen in low birthweights, criminal sentencing and income deprivation. London shows some specific features, exhibiting lower take-up for the main childhood immunisations, but a higher birth rate than all other regions and countries of the UK.

However, data at sub-regional geographic levels often illustrate more accurately the variations between areas. For example, the highest levels of educational attainment at age 16 were found in local authorities in most regions. Many trends in child-related issues also appear related to level of income deprivation and rurality of the area where children are resident. For example, prevalence of childhood obesity, proportion of children in workless households and patterns in household income deprivation all suggest possible trends dependent upon these factors.

\section{Introduction}

How do the lives of children and younger people vary in different parts of the UK? What are the regional and subregional differences in educational achievement, criminal activity and health - such as levels of immunisation and obesity? Are there differences between the experiences of those growing up in urban or rural areas of England?

This article aims to look at how the lives of children vary regionally, following on from the publication of the Children's Plan (2007) by the Department for Children, Schools and Families (DCSF). In line with the Plan it covers, where possible, children and young people up to the age of 19 .

Children and young people are being brought up today against the backdrop of an UK population which is growing in size and becoming older on average. They are now making up a smaller proportion of the population than ever before. In 2007 for the first time, the proportion of the UK population aged under 16 was less than the proportion of state pension age (SPA). This applied to most countries of the UK and regions of England, except London and Northern Ireland.

In exploring geographical diversity in children and young people's educational attainment, health, and juvenile sentencing, the article finds interesting differences at regional level. But at sub-regional levels the variation is generally greater and so sample analyses at local authority and neighbourhood level are also presented. An increasing policy focus on addressing inequalities at community level has resulted in new measures becoming available for local authority or smaller areas - many as National Statistics. The Rural and Urban Area Classification (RUAC - see Glossary) has also been attached to various indicators, allowing the exploration of differences between the experience of those growing up in urban and rural areas in England.

Understanding the impact of poverty and deprivation on well-being and development is central to developing government policy on children. The article shows clear geographical variations in accepted measures of deprivation. For example, data relating educational attainment to the Income Deprivation Affecting Children Index (IDACI) shows considerable variability in educational attainment once area deprivation has been taken into account.

1 The authors would like to thank colleagues in contributing Departments and other organisations for their generous support and helpful comments without which this article would not have been possible. 


\section{Figure 1.1 Difference in the proportion of the population aged under 20 between the regions/countries and the UK', 2007}

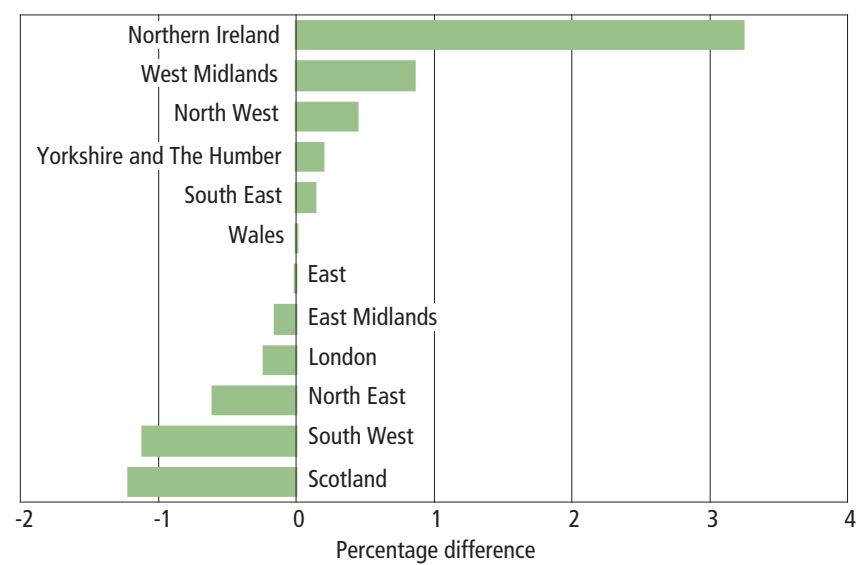

124.2 per cent of the UK population were under 20 years of age in 2007. Source: Office for National Statistics

Although partly inspired by government policy in England, this article attempts to portray the under 20-year-old population for the whole of the UK. However, where this has not been possible, the article attempts to provide pointers to the policies and statistics pertaining to the other countries.

\section{Population}

In the five year period up to 2007 the UK population increased by 2.8 per cent from 59 million to 61 million. The population aged below 20 remained roughly constant, at just under 15 million. As with the total population, more children and young people lived in the South East ( 2 million) than in any other country of the UK or region of England, followed by London (1.8 million) and the North West (1.7 million). The North East, Wales and Northern Ireland had the smallest total numbers of people under 20 years old with between 480,000 and 720,000 each.

In 2007 almost one in four (24 per cent) of the total UK population was aged under 20, with 7.2 million females and 7.6 million males. Northern Ireland had the highest proportion of people under 20 (27 per cent), while Scotland and the South West had the lowest proportions in the age group (Figure 1.1).

Nearly 82 per cent of people under 20 years old in England lived in 'Urban' areas (Figure 1.2) according to RUAC. A further 9 per cent each lived in areas classed as 'Town and Fringe' and 'Village, Hamlet \& Isolated Dwellings'. Information on urban/ rural classification of areas in Northern Ireland, Scotland and Wales is available from their websites (see References).

Population by age

The under-20 population may be broken down into four age groups - children under five, five to nine, ten to 14 and 15 to 19. In all countries and regions except London, the number of

\section{Figure 1.2 Population aged under 20 by Rural and Urban Area Classification at LSOA level, England, 2007}

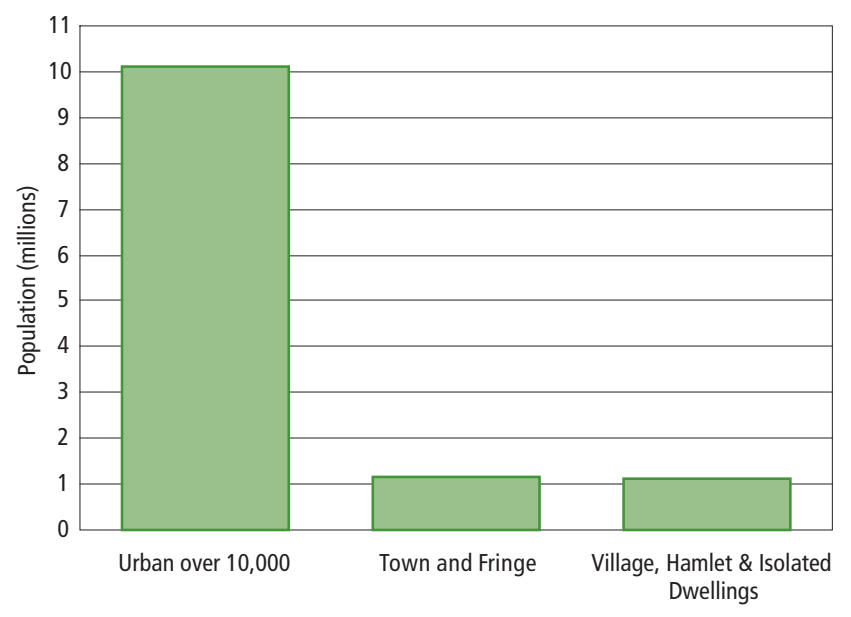

Source: Communities and Local Government; Office for National Statistics

individuals aged under 20 was evenly spread across all five-year age groups, with each of the four groups contributing around one quarter. In London however, children under five accounted for 29 per cent of the population (Figure 1.3).

The high proportion of children aged under five years old in London in 2007 is a consequence of the relatively large numbers of births in London in recent years. In 2007 the birth rate in London was 16.6 births per 1,000 population compared with an average of 12.7 for the whole of the UK (Online table 6.1). This is mainly due to the age structure of the London population, where there have been proportionally large numbers of women at the peak childbearing ages (25-39 years). Families moving out of London as their children grow older (see migration section below) may also have contributed to proportionally lower numbers of children aged five to 19 years.

At local authority level, high numbers of births relative to the total population were seen in and around urban centres. Local authorities with birth rates above 16 per 1,000 population included many London boroughs, Manchester, Bradford, Birmingham, Peterborough, Luton and Southampton (Online table 6.2).

\section{Migration}

In addition to births (and deaths - see Health section), the other main element of population change in an area is migration, but this is a relatively small component for children and young people. In 2006, 42,000 children under 15 years old arrived from another part of the world to live in the UK. Of these, 38,000 came to England. However, 26,000 children left the UK to live abroad, leaving a net inflow of $16,000(14,000$ to England). Of these, 8,000 children under 15 arrived in London, but the net increase in the population due to international migration was only 4,000 because of an outflow of 4,000 children. 


\section{Figure 1.3 Composition of under-20 population, by five year age band, 2007}

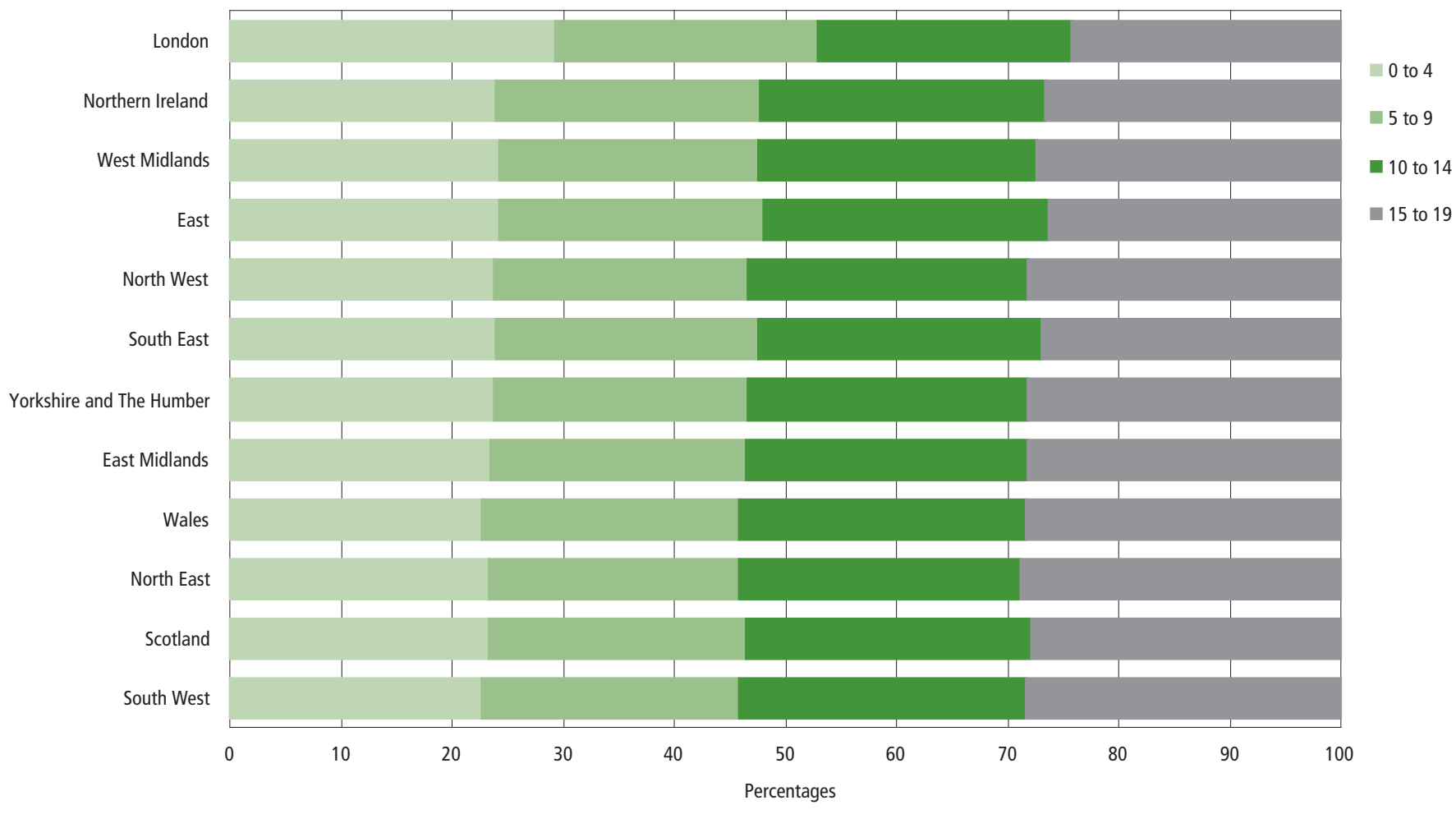

Source: Office for National Statistics

Children moving house (with their parents) between regions of England and countries of the UK (internal migration) constitutes a larger proportion of migration than international migration. London experienced the largest changes resulting from internal migration between mid-2006 and mid-2007 among both the under 15-year-old and 15 to 19 age groups.

In the under 15-year-old age group London experienced a net outflow, and other regions in the south of England experienced a net inflow. A balance of 29,000 left London, with the South East experiencing the largest net gain $(8,500)$, followed by the South West $(7,000)$ and East of England $(5,600)$. In the 15 to 19 age group, a balance of 35,000 left London and increases were recorded in the South West (net inflow 8,300), Yorkshire and The Humber, South East and East Midlands (all over 5,500). North West and West Midlands also recorded net reductions of approximately 1,000 each in the 15 to 19 age group.

\section{Ethnicity}

Experimental statistics for England show that in 2006 London had the highest number of young people aged under 20 in minority ethnic groups (non-White), with 714,000 individuals (40 per cent of London's population aged under 20). The next highest was the West Midlands with 255,000 (19 per cent). North East and South West had the lowest numbers, with 33,000 (5 per cent) and 67,000 (6 per cent) respectively.

Asian/Asian British and Black/Black British accounted for 15 per cent and 14 per cent respectively of London's population aged under 20. In the West Midlands over 11 per cent those under 20 years old were Asian/Asian British.

Family composition and size

There were almost 7.5 million families with dependent children (see Glossary) in the UK in 2008. Figure 1.4 shows the regional diversity in the number of dependent children in the family, while the variation by family composition is shown in Figure 1.5.

Almost half (46 per cent) of families with dependent children in the UK contained only one dependent child, with no individual region or country dropping below 40 per cent in 2008. The highest proportion was 53 per cent in the North East (the only one above 50 per cent), while the lowest was in Northern Ireland at 40 per cent. In most regions the proportion of families with two dependent children was close to the UK average of 39 per cent. A dependent child family was least likely to have two dependent children in the North East (35 per cent), followed by London (37 per cent). Families with three or more dependent children accounted for the smallest proportion of families with dependent children in all regions and countries of the UK, with the UK average being 15 per cent. Northern Ireland had the highest proportion (20 per cent), while North East and Scotland had the lowest (12 per cent).

It should be noted, however, that these figures do not represent completed family sizes, but are a snapshot of families with dependent children at a point in time.

In the UK, married couple families made up 61 per cent of all 


\section{Figure 1.4 Family composition by number of dependent children', second quarter, 2008}

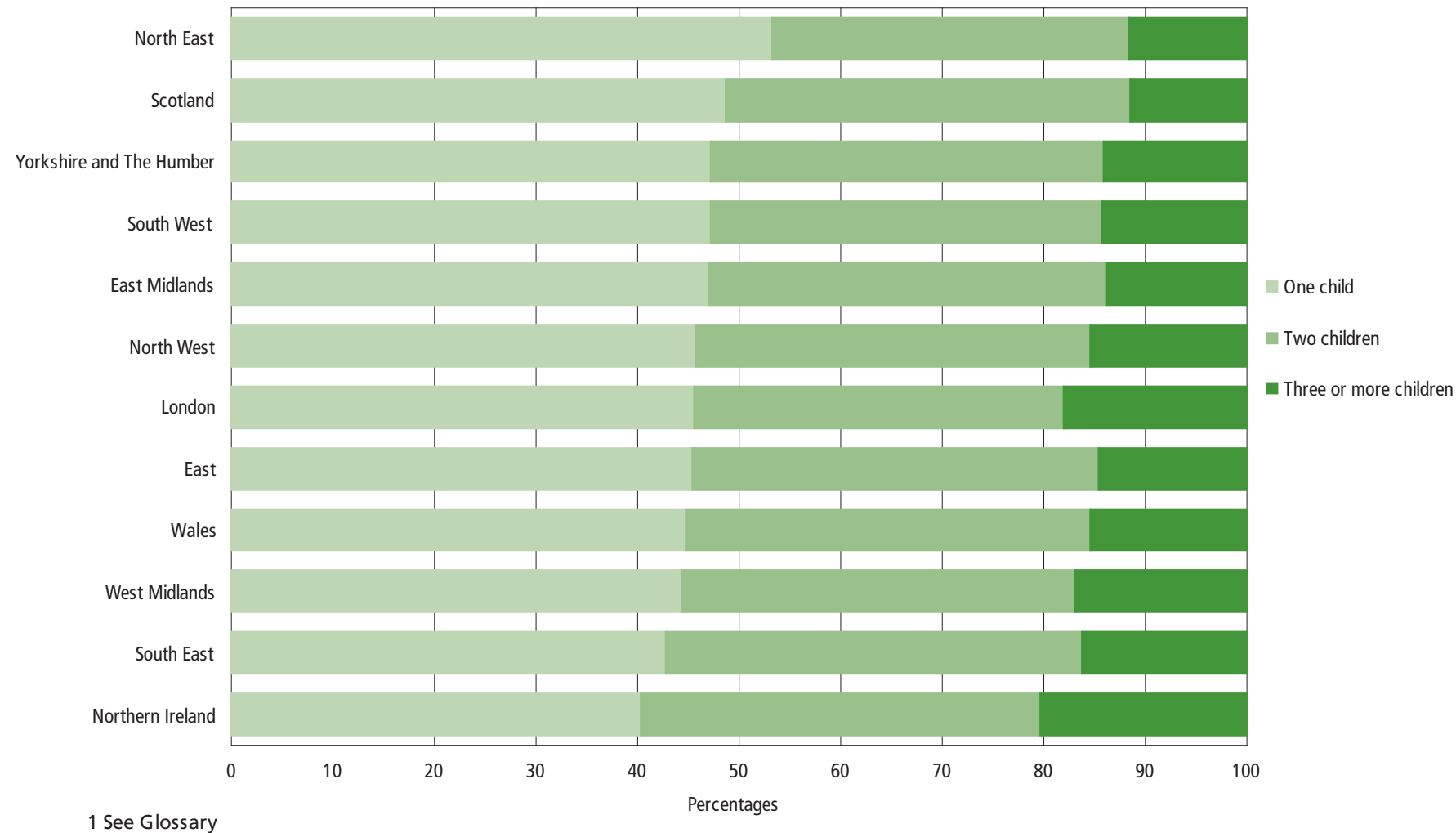

Source: Labour Force Survey, Office for National Statistics

families with dependent children, while cohabiting couple families were 14 per cent. Countries and regions with higher proportions of married couple families tend to have lower proportions of cohabiting couple families. For example in the
North East, married couple families were 54 per cent of all families with dependent children, and cohabiting couple families were 17 per cent. Equivalent proportions for Northern Ireland were 67 per cent and 9 per cent respectively.

\section{Figure 1.5 Proportion of families with dependent children by type, second quarter, 2008}

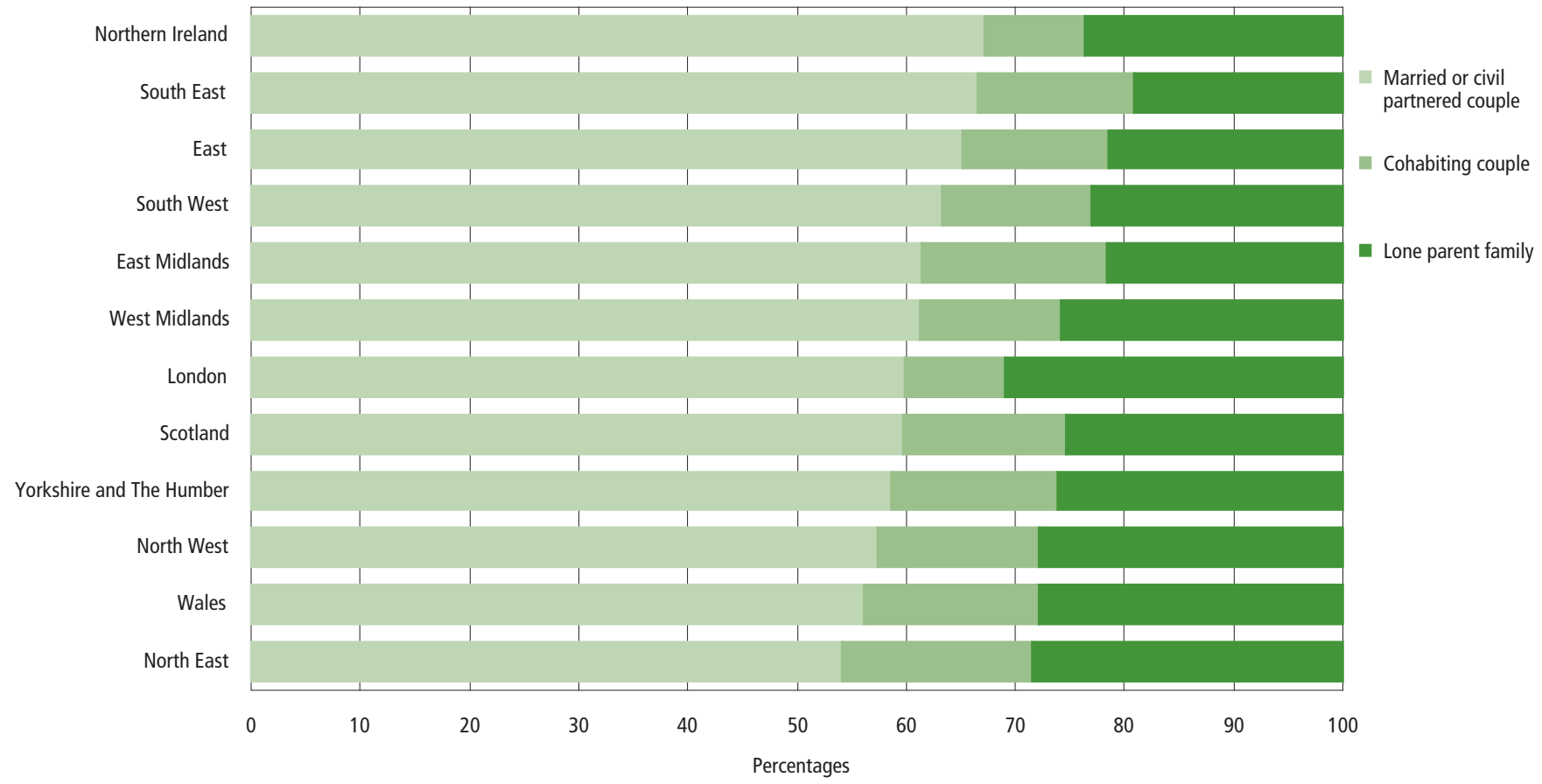


The exception was London, where dependent child families were more likely to be headed by a lone parent (31 per cent) than in any other region or country. Other regions or countries with high proportions included the North East (29 per cent), Wales and the North West (both 28 per cent), compared with the UK value of 25 per cent. Lowest proportions of dependent child families headed by a lone parent were found in the South East, East of England and the East Midlands (all less than 22 per cent).

\section{Children in poverty in the UK}

This section explores variations in the percentage of children in low income families and in households dependent on benefits at a regional level. It also considers how poverty varies according to the rural/urban nature of the area within which they live.

In 2006/07 the UK proportion of children living in households with incomes below 60 per cent of median equivalised household income (before housing costs; see Box 1) was 22 per cent.

\section{Box 1 Measuring child poverty}

A target to reduce child poverty to a minimum within a generation by 2020 was formally set by government in 2004 (Child Poverty Review, HM Treasury, 2004). Measuring Child Poverty (Department for Work and Pensions, 2003) outlined the government's three indicators of child poverty. These were:

1 the number of children in absolute low-income households (families with incomes below a particular threshold when adjusted for inflation, set at $£ 195$ per week for a couple in 2006/07 prices);

2 the number of children in relative low income households, measured as the number of children living in households below 60 per cent of contemporary median equivalised household income, and;

3 the number of children in relative low-income households and in material deprivation, measured as number of children living in households that are both materially deprived and have an income below 70 per cent of contemporary median equivalised household income.

The Government has recently outlined its proposed definition of eradication of child poverty (HM Government, 2009), which incorporates the second and third indicators listed above, and additionally a measure of persistent poverty. In addition, views were being sought on whether the inclusion of an absolute low income indicator would provide additional value to the measures of success.

The standard measures for household and child deprivation in the UK are published in the Households Below Average Income (HBAI) series. This provides analysis of the incomes of households with dependent children including those in low income households. National estimates are available on a single year basis; however regional estimates are presented using threeyear averages, as single year estimates for regions tend to be volatile.

Further notes on HBAI may be found in the Notes and Definitions for Income and Lifestyles Online tables. Full data and notes on methods may be found in Table 4.6 of the Households Below Average Income report (Department for Work and Pensions).

To measure material deprivation in households, families surveyed in the Family Resources Survey are asked if they have access to a list of specific goods and services. These are summarised below in terms of whether they reflect adult $(A)$ or child $(C)$ material deprivation.

- A holiday away from home for one week a year with his or her family $(C) /$ not with relatives $(A)$

- Replace any worn out furniture (A)

- A small amount of money to spend each week on yourself, not on your family (A)

- Regular savings (of $f 10$ pounds a month) for rainy days or retirement $(A)$

- Insurance of contents of dwelling (A)

- Have friends round for tea or a snack once a fortnight (C)/a drink or meal at least once a month(A)

- A hobby or leisure activity (A/C)

- Replace or repair broken electrical goods such as refrigerator or washing machine $(A)$

- Keep your home adequately warm (A)

- Two pairs of all weather shoes for each adult (A)

- Enough money to keep your home in a decent state of repair (A)

- Swimming at least once a month (C)

- Enough bedrooms for every child over 10 of different sex to have his or her own bedroom (C)

- Leisure equipment such as sports equipment or a bicycle (C)

- Celebrations on special occasions such as birthdays Christmas or other religious festivals (C)

- Play group/nursery/toddler group at least once a week for preschool aged children, or, going on a school trip at least once a term for school aged children (C)

Scores are combined using a prevalence weighted approach, in which more weight in the deprivation measure is given to families lacking those items that most families already have. 
Map 1.6

\section{Proportion of children living in low income households ${ }^{1}$ by regions, 2004/05 to 2006/07}

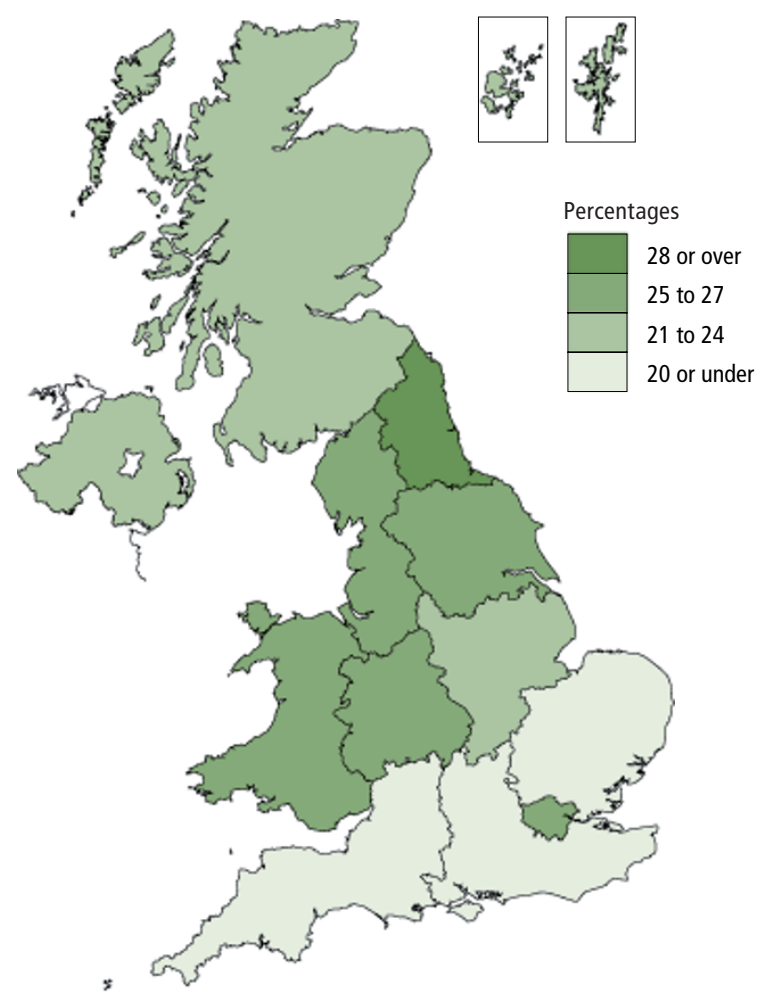

1 Households below 60 per cent of median equivalised household income before housing costs. See Notes and Definitions online.

Source: Department for Work and Pensions

Map 1.6 shows regional proportions of children in low income households (see Box 1) over the period 2004/05 to 2006/07. Highest proportions were in North East (28 per cent) and West Midlands (26 per cent) and London (25 per cent). However, there was a large variation between inner and outer London at 31 per cent and 22 per cent respectively. The lowest estimates were the East of England, South East and South West at 17 per cent or less.

Map 1.7 illustrates the combined measure for numbers of children in relative low-income households and in material deprivation (see Box 1). The geographic trends shown in Map 1.7 are broadly similar to those of Map 1.6. The highest level of combined income and material deprivation was found in London (22 per cent) compared with a UK average of 16 per cent.

The final indicator - absolute low household income - is used to measure changes in UK child poverty. This shows that absolute poverty has decreased in all regions and countries of the UK since $1998 / 99$ to $2000 / 01$.

\section{Workless households}

Child income-deprivation can also be measured by the proportion of children living in workless households (see Glossary). This is indicative of the household being dependent on income support or out of work benefits.
Map 1.7 Proportion of children living in households that are low income and materially deprived ${ }^{1}$ by region, 2004/05 to 2006/07

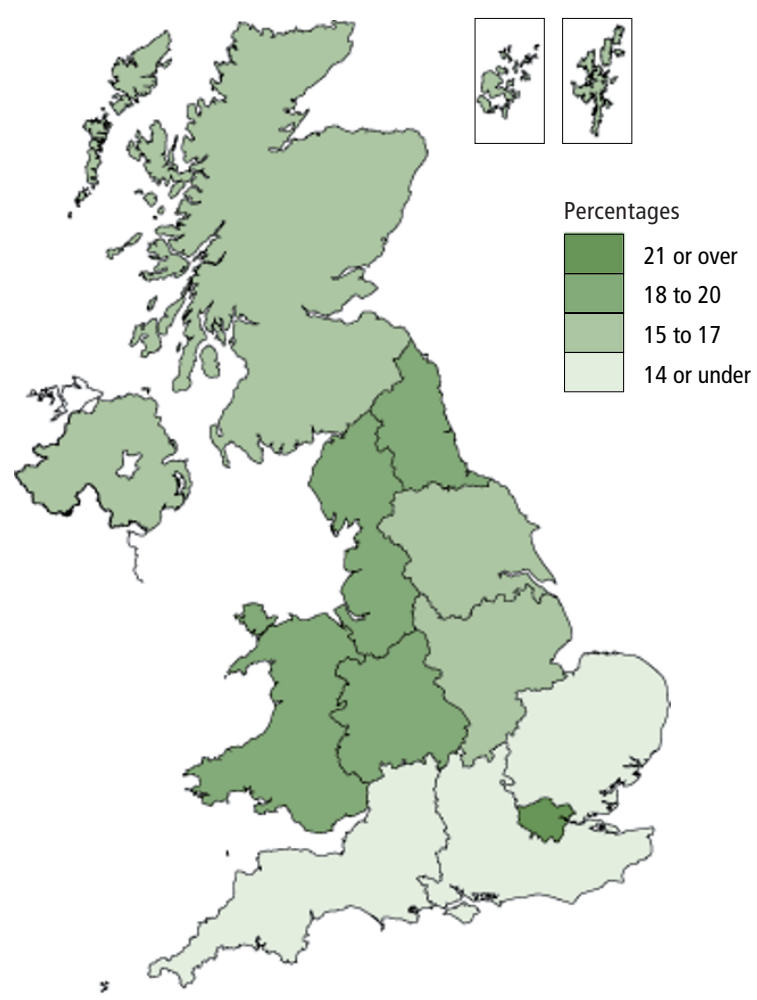

1 Households with a material deprivation score of 25 or more and a household income below 70 per cent median equivalised income before housing costs. See Notes and Definitions online and Box 1.

\section{Source: Department for Work and Pensions}

The northern regions and London again tend to have above average proportions, compared with the UK mean value of 15 per cent (Figure 1.8; Online table 8.6). Almost one in four children (23 per cent) in London and nearly one in five (18 per cent) in Wales, the North East, North West and West Midlands

\section{Figure 1.8 Children ${ }^{1}$ living in workless ${ }^{2}$} households, 2007

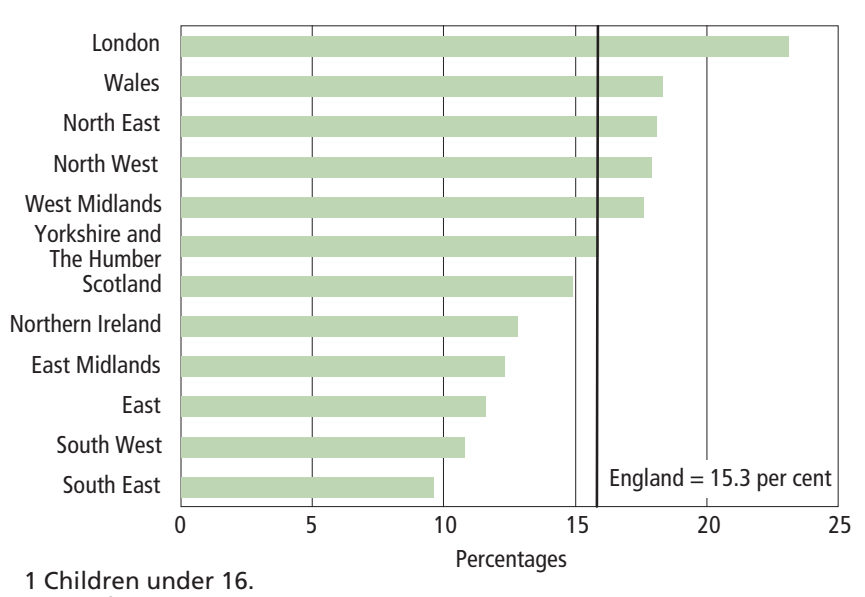

2 See Glossary.

Source: Annual Population Survey household data set, Office for National Statistics 
lived in workless households in 2007. South East had the lowest proportion at just under 10 per cent.

\section{Income Deprivation Affecting Children Index}

The Income Deprivation Affecting Children Index (IDACI) (see Box 2) is based on the proportion of children aged 0 to 15 living in income-deprived households at the Lower Layer Super Output Area (LSOA) level (see Glossary) in England. This index enables further investigation of the geographic distribution of the child population of England in terms of deprivation, although it uses a slightly different measure to those discussed in the previous paragraphs.

Nevertheless, the regional pattern is very similar to the other poverty measures. London has over a quarter (27 per cent) of its under 20-year population living in LSOAs in the most deprived decile of IDACI (see Box 3). A further four regions have more than 12 per cent of under 20 -year-olds living in the 10 per cent most deprived LSOAs in England (North West, 17 per cent; West Midlands, 16 per cent; North East, 15 per cent; Yorkshire and The Humber, 13 per cent). In the South East, East of England and South West only 3 or 4 per cent of this age group lived in the most income deprived LSOAs (Figure 1.9).

\section{Box 2 The Income Deprivation Affecting Children Index}

The Income Deprivation Affecting Children Index (IDACI) was developed by Communities and Local Government (CLG) as part of the Indices of Deprivation (also see Understanding patterns of deprivation on page 93). IDACl covers children aged between 0 and 15 (inclusive) living in households receiving Income Support, [Income-Based] Job Seekers Allowance, Pensions Credit; or those not in receipt of these benefits but in receipt of Working Tax Credit or Child Tax Credit with an equivalised income below 60 per cent of the national median before housing costs. The IDACI score is the proportion of children aged between 0 and 15 living in such households as a proportion of all children aged between 0 and 15. The index is not a National Statistic although the underlying data are.

IDACI is calculated at Lower Layer Super Output Area (LSOA) level. LSOAs are ranked on their IDACI score according to their position relative to all other LSOAs in England. They can be divided into 10 equal-sized groups (deciles), with decile 1 being the most deprived and 10 being the least deprived.

As analysis at LSOA level is very detailed, London and the North East region have been selected as examples of how child populations at risk of deprivation (or the side-effects of living in neighbourhoods with high levels of income deprivation) can be located using a small-scale geography.
Figure 1.9 Population under 20-years-old in the 10 per cent most deprived LSOAs', by region, 2007

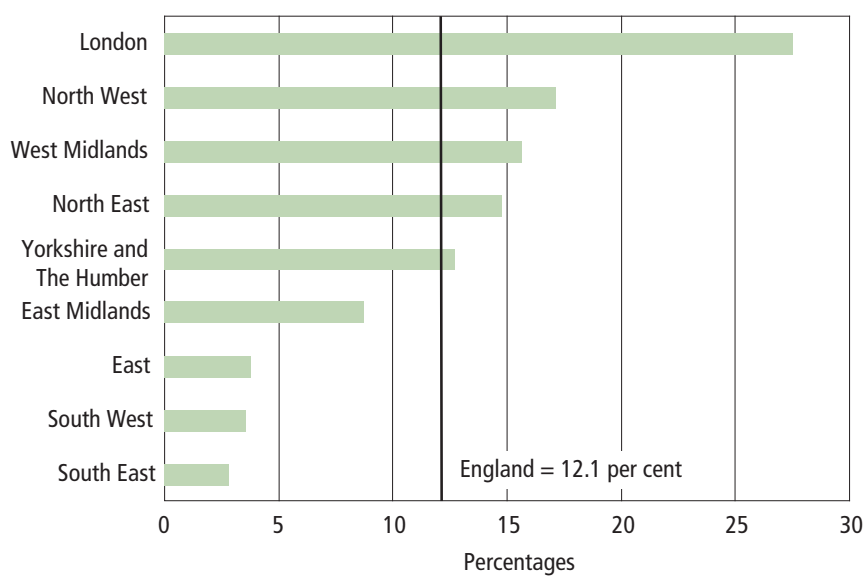

1 As defined in the Income Deprivation Affecting Children Index (IDACI; see Box 2).

\section{Source: Office for National Statistics; Communities for Local Government}

\section{Box 3 Child age groups used}

IDACI defines child poverty with respect to the 0 to $15-$ year-old (inclusive) population, for England only, at the Lower Super Output Area (LSOA) level. However, midyear 2007 population estimates at this lower geographic level obtained for use elsewhere in the article are for the 0 to 19 -year-old population. Therefore this wider age group has been used to determine population estimates for the 10 most and least deprived LSOAs.

Focusing on London (Map 1.10), nearly one quarter of the LSOAs in this region were in the 10 per cent most deprived in England according to IDACl, well above what would be expected if poverty was evenly spread across the regions. Together the most deprived LSOAs accounted for 498,000 children under 20 years old, which represents 28 per cent of this sub-population in London. A large proportion of these LSOAs are located north of the Thames, clustered in the north east quadrant of London around Tottenham, Hackney, Shoreditch and West Ham, for example. Further clusters can also be found in North West London, for example Camden Town and spreading north west from Paddington, along with a scattering south of the Thames, mainly in inner London, for example Battersea, Brixton, Camberwell, Bermondsey, Lewisham and Woolwich.

Conversely, only 5 per cent of London's LSOAs are present in the 10 per cent least deprived LSOAs in England, accounting for 79,000 of London's 0 to 19-year-olds, equal to only 4 per cent of this region's under-20 population. These LSOAs tend to be larger in land area and located towards the south of outer London around Richmond, Wimbledon, Twickenham and 
Map 1.10 The 10 per cent most and least deprived LSOAs', London, 2007

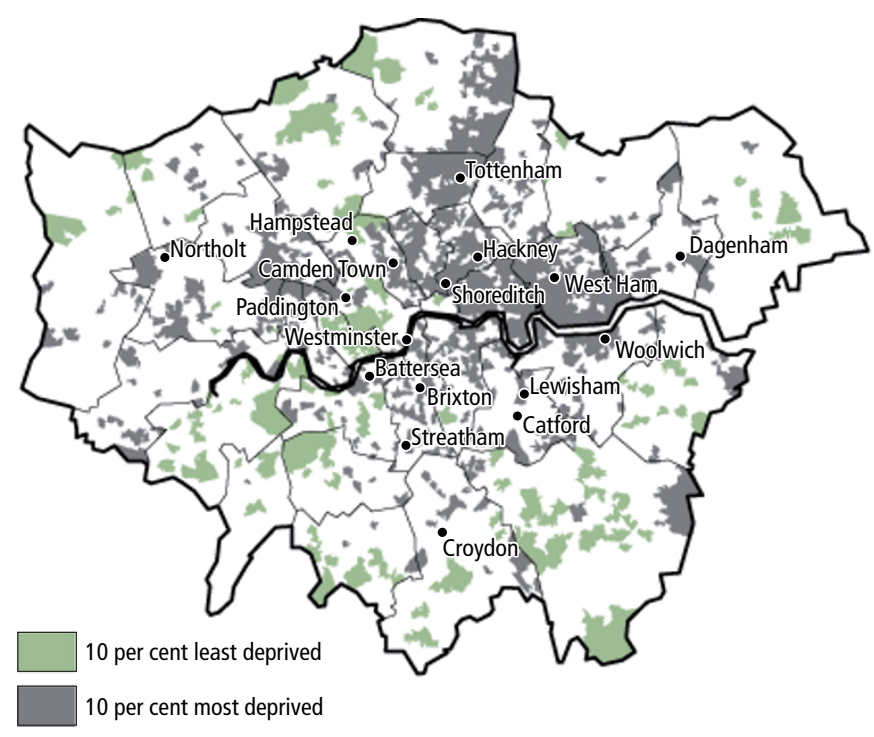

1 Most or least deprived in England according to the Income Deprivation Affecting Children Index. See Box 2.

\section{Source: Communities and Local Government}

Purley and isolated high levels to the north and west around Kensington and Chelsea, Hampstead and Barnet and Uxbridge.

The North East region (Map 1.11) presents a contrasting situation as it includes both rural areas and important urban centres. Despite similar proportions of children in the two regions being in poverty on the other measures, the spread of LSOAs in the most deprived 10 per cent on IDACI in the North East is significantly different from London's.

About one in eight (13 per cent) of LSOAs in the North East were among the most deprived 10 per cent in England. The North East had the smallest under-20 population in 2007 $(605,000)$ and these LSOAs contained 89,000 (15 per cent) of them, However, 10 per cent of the North East's LSOAs are present in England's 10 per cent least deprived LSOAs on IDACl, containing 10 per cent of the region's under-20 population, so remaining proportional to the national spread of income-deprivation.

Both the most deprived and least deprived LSOAs of the North East region populate the eastern side of this region. The most deprived LSOAs tend to be located nearer the coast, in the larger urban centres, for example Middlesbrough, Hartlepool, Newcastle-upon-Tyne, Blyth and Ashington. The least deprived LSOAs tend to be located towards central parts, and are clustered together in six main areas: west of Darlington; west of Hartlepool; southeast of Consett; northwest of Newcastleupon-Tyne; Hexham and Corbridge; and running northeast from Morpeth to the north east coast. Comparison with the map in the article Understanding patterns of deprivation on
Map 1.11 The 10 per cent most and least deprived LSOAs' ${ }^{1}$, North East, 2007

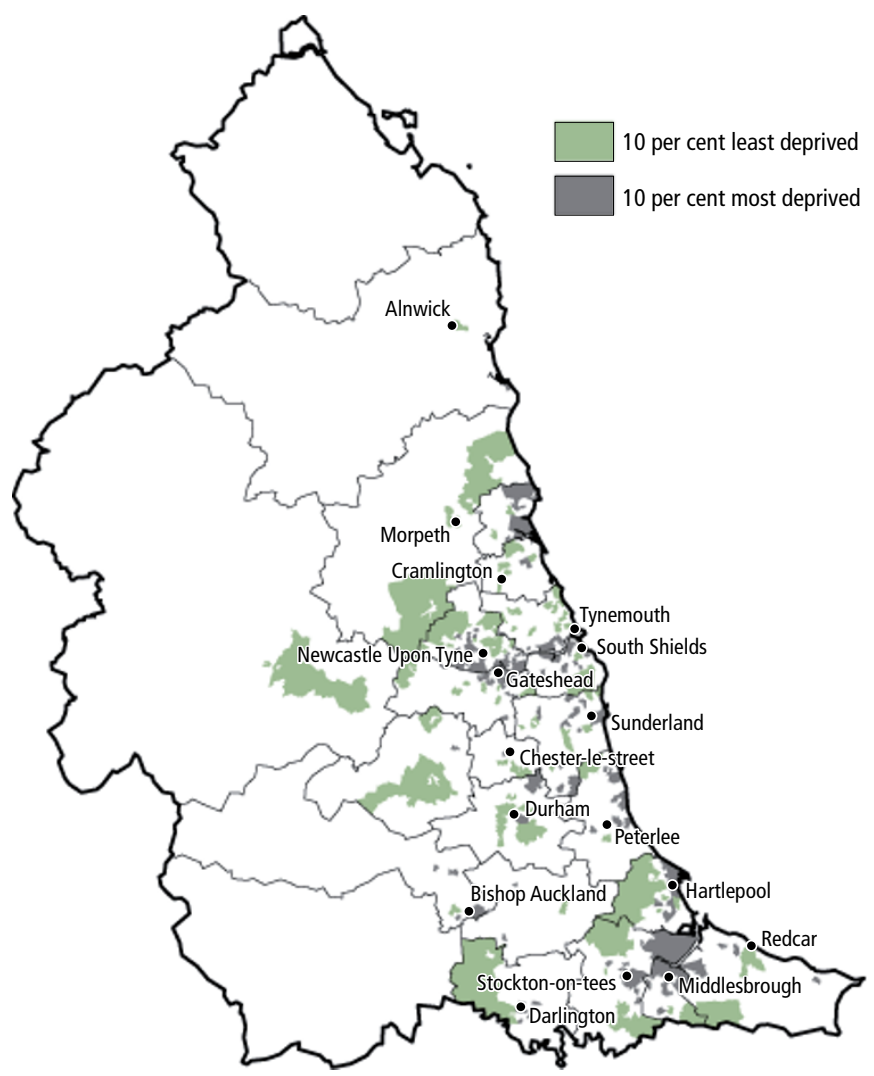

1 Most or least deprived in England according to the Income Deprivation Affecting Children Index. See Box 2.

Source: Communities and Local Government

page 93 reveals these to be mainly Town and Fringe areas on RUAC. Notably, the most rural areas of the region are neither most or least deprived.

Children in deprived areas by the Rural and Urban Area Classification

IDACI also allows these small geographic areas and their young populations to be categorised by RUAC. In 2007 nearly 1.5 million 0 to 19 -year-olds lived in the 10 per cent most deprived LSOAs in England. Over 99 per cent of these were living in areas classed as Urban. However, the majority of children in the least deprived LSOAs were also more likely to be found in Urban areas, with 76 per cent $(929,000)$ of all children in the least deprived decile living in such areas. The remaining 24 per cent of children in the least deprived decile were divided fairly equally between Town and Fringe, and Village, Hamlet \& Isolated Dwellings.

Figure 1.12 compares the deprivation distributions of LSOAs according to IDACI for the three main settlement types in RUAC. The three more sparse categories have been excluded as these account for only about 1 per cent of the child population in England.

A child in an Urban area is more likely to live in a deprived 
Figure 1.12 Under-20 population by IDACI ${ }^{1}$ decile and Rural and Urban Area Classification ${ }^{2}$, England, 2007

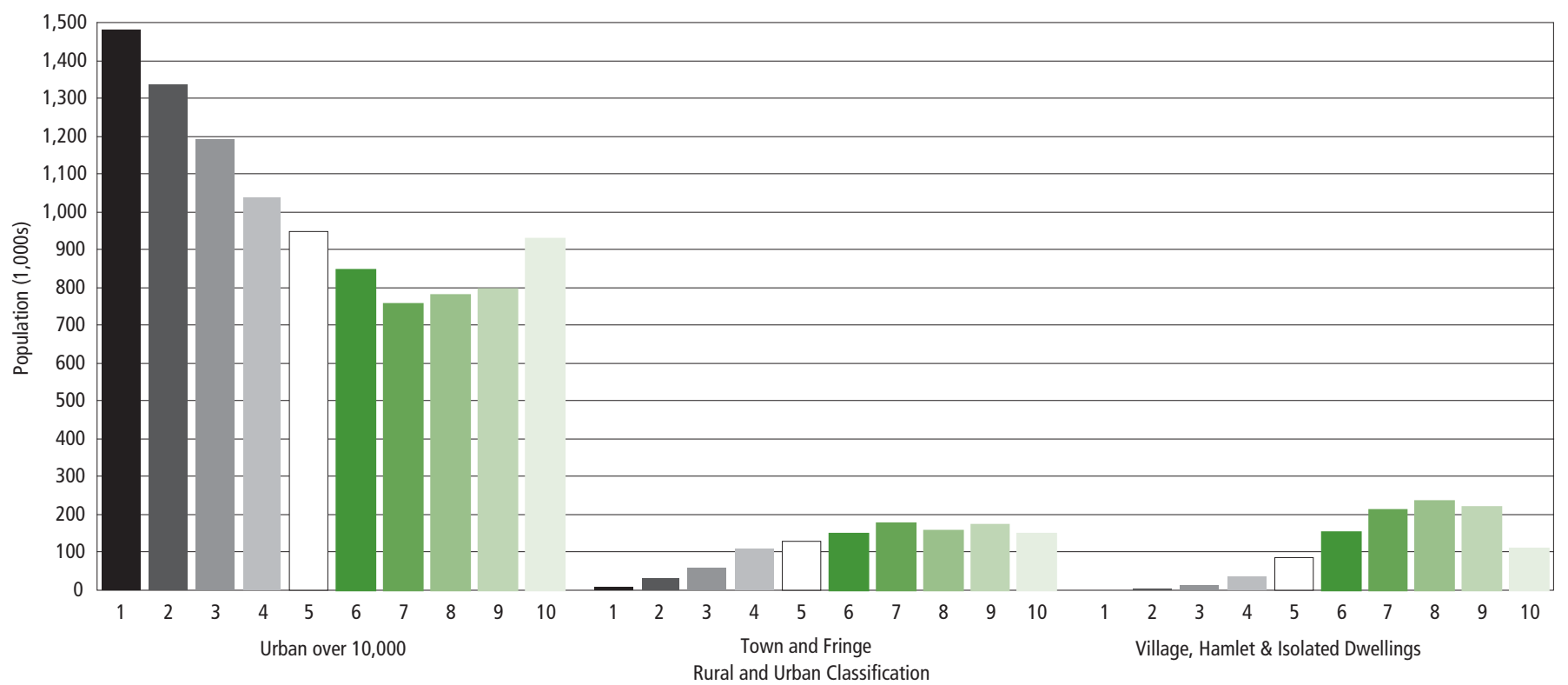

1 Income Deprivation Affecting Children Index. See Box 2.

2 Categorised at Lower Layer Super Output Area level.

Source: Communities and Local Government; Office for National Statistics

neighbourhood than a child who lives in a small town or a village. Those living in Urban areas are more likely to live in the more deprived LSOAs. In the bottom half of the IDACI distribution each subsequent more deprived decile contains more children than the previous one. This trend reverses for the less urbanised and rural areas; in both, children tend to be in the least deprived half of IDACl, with reducing numbers in the more deprived deciles.

\section{Education and training}

This section considers key statistics for each phase of education (see Box 4) and reports trends and characteristics at a regional and sub-regional level. Variation according to rural-urban character and income deprivation of the local area are explored for Key Stage 4 attainment in England as an example, although similar analyses could be done for earlier Stages. It also briefly looks at pupil absences from school.

\section{Early years}

Figure 1.13 (Online table 4.2) shows participation rates for three- and four-year-olds by type of early years education provider. In January 2007, 1.1 million three- and four-year-olds in England benefited from some form of early education at either maintained schools or in the private, voluntary or independent sector (see Box 5).

In all regions of England participation rates for three- and fouryear-olds were close to 100 per cent, and in some cases exceeded 100 per cent due to some pupils being registered with two different education providers. The figures for other countries may not be comparable and in particular that for Wales (85 per cent) covers schools provision only.

\section{Box 4 Education in the UK}

A young person's education in England, Wales or Northern Ireland typically consists of four key stages; Foundation, Primary, Secondary (to the age of 16) and post-16. Primary (from age of five) and Secondary (age 11 to 16$)$ are mandatory for all children and are split into four individual 'Key Stage' assessment periods (KS1, KS2, KS3 and KS4). KS1 and KS2 occur during Primary years, while KS3 and KS4 are in Secondary school learning, the latter being measured through GCSE examinations and other equivalent qualifications. A further level, unofficially labelled KS5, can be experienced after the age of 16 if a young person decides to undertake it. Legislation has also been passed recently to raise the education participation age to 17 by 2013 and 18 by 2015 .

The educational system in Scotland is different, although pupils go through similar stages of pre-school, primary and secondary education. Pupils aged around 15/16 are examined through a range of National Qualifications, usually taking Standard Grades over the third and fourth years of secondary school. They can also take qualifications at Access 1, 2 and 3 and at Intermediate 1 and 2 at this stage (although Intermediate qualifications were originally designed for an older age group). Standard Grade and Intermediate qualifications are broadly comparable to GCSEs in England, Wales and Northern Ireland (also see Glossary and Notes and Definitions to Online tables). 


\section{Box 5 Early years and foundation stage}

In England all children are eligible for a free part-time funded place from 1 September, 1 January or 1 April following their third birthday for up to two years before they reach statutory school age. Free places can be accessed in a variety of settings including nursery and reception classes; playgroups; pre-schools; in nurseries; and with accredited childminders. A local authorityfunded place consists of a minimum of 12.5 hours of early education per week for thirty-eight weeks of the year.

In Wales, all 3-year-olds are guaranteed a free half-time place if their parents want one. This does not have to be in a school. There are no policy 'barriers' that limit the number of under-4s that go into education.

In Scotland, all children aged three and four years old are eligible for a free part-time pre-school place. The entitlement starts from the beginning of the school term immediately following the child's third birthday and continues until the end of the school term before they are eligible to start primary school. Local authorities provide pre-school education in the form of nursery classes in primary schools and nursery schools. They also make arrangements with private and voluntary centres to ensure that there are enough places available to meet demand.

Headcounts used in Figure 1.13 are for children aged three and four at 31 December 2006, but may include some two-year-olds in schools. Children attending more than one provider may have been counted more than once. In Scotland, headcounts reflect January registrations for ante-pre-school education (three- to four-year-olds).

The Foundation Stage curriculum is a statutory stage of the National Curriculum for England, and consists of 13 assessment scales in six areas of learning covering children's physical, intellectual, emotional and social development. Foundation Stage Profile captures the Early Learning Goals as the combined set of these 13 assessment scales; each scale has nine points, and a pupil's progress is characterised by the points achieved on a scale.

In Wales, rollout of the Foundation Phase began in September 2008. The Foundation Phase is a new approach to learning for children from three to seven years of age and will replace Key Stage 1 by September 2012. The Foundation Phase places great emphasis on children learning through play and active involvement rather than by completing exercises in books, and focuses on seven areas of learning covering similar aspects to a child's physical, intellectual, emotional and social development as in England.
Generally, higher proportions of three- and four-year-olds attend maintained nursery and primary schools than private and voluntary provision. In England only South West and South East regions bucked this trend in 2007 with private and voluntary sector participation rates of 61 per cent and 55 per cent respectively. The lowest take up rates for voluntary and private services were in North East (16 per cent) and London (24 per cent).

The Foundation Stage Profile (see Box 5) assessment in England for 2007 found that 46 per cent of children in England achieved a 'Good' level of development at the end of the foundation year in which they turned five. The North West and South West regions achieved the highest success rate (49 per cent and 48 per cent respectively). Nationally, 27 local authorities achieved the target of 53 per cent of children attaining a 'good' level of development (Map 1.14).

\section{Primary years}

There were 4.8 million full-time equivalent (FTE) pupils in UK public sector primary schools in 2006/07. South East and London contained the highest number of pupils with 609,000 and 602,000 respectively, followed by the North West $(568,000)$.

\section{Box 6 Primary school assessment}

In England, Wales and Northern Ireland pupils are assessed via a combination of teacher observations and tests. During KS1 (up to age seven) pupils are only tested in Maths and Science in England, with Wales and Northern Ireland extending assessment to English also. Once they reach Key Stage 2 tests in England extend to include English. Level 4 is the target attainment level of eight levels defined in the core Key Stage 2 skills of Mathematics, Writing and Reading.

Scotland uses 'professional responsibility for assessment' building on the key principles of the Assessment is for Learning (AifL) programme. They are developing a system of assessment which will support learning across three to 18 years as part of the Curriculum for Excellence programme.

The highest proportions of primary school classes with over 30 pupils in 2006/07 were in the South West and East Midlands (15 per cent), compared with the England average of 12 per cent. North West, Yorkshire and The Humber and South East also exceeded the England value, each with 14 per cent of their classes larger than the guide target. Northern Ireland had the lowest percentage at only 5 per cent, while London and Wales (6 per cent) and Scotland (7 per cent) were the only others below 10 per cent. (Online table 4.4)

Key Stage attainment at Mathematics provides a simple measure of how pupils fare in each of the regions as they progress from KS1 to KS2 as it is examined at both attainment levels (Online table 4.7, see also Box 6). At KS1 the highest regional proportions of pupils reaching target attainment levels 


\section{Figure 1.13 Participation rates for three- and four-year-olds ${ }^{1}$ by selected type of early education provider², 2007}

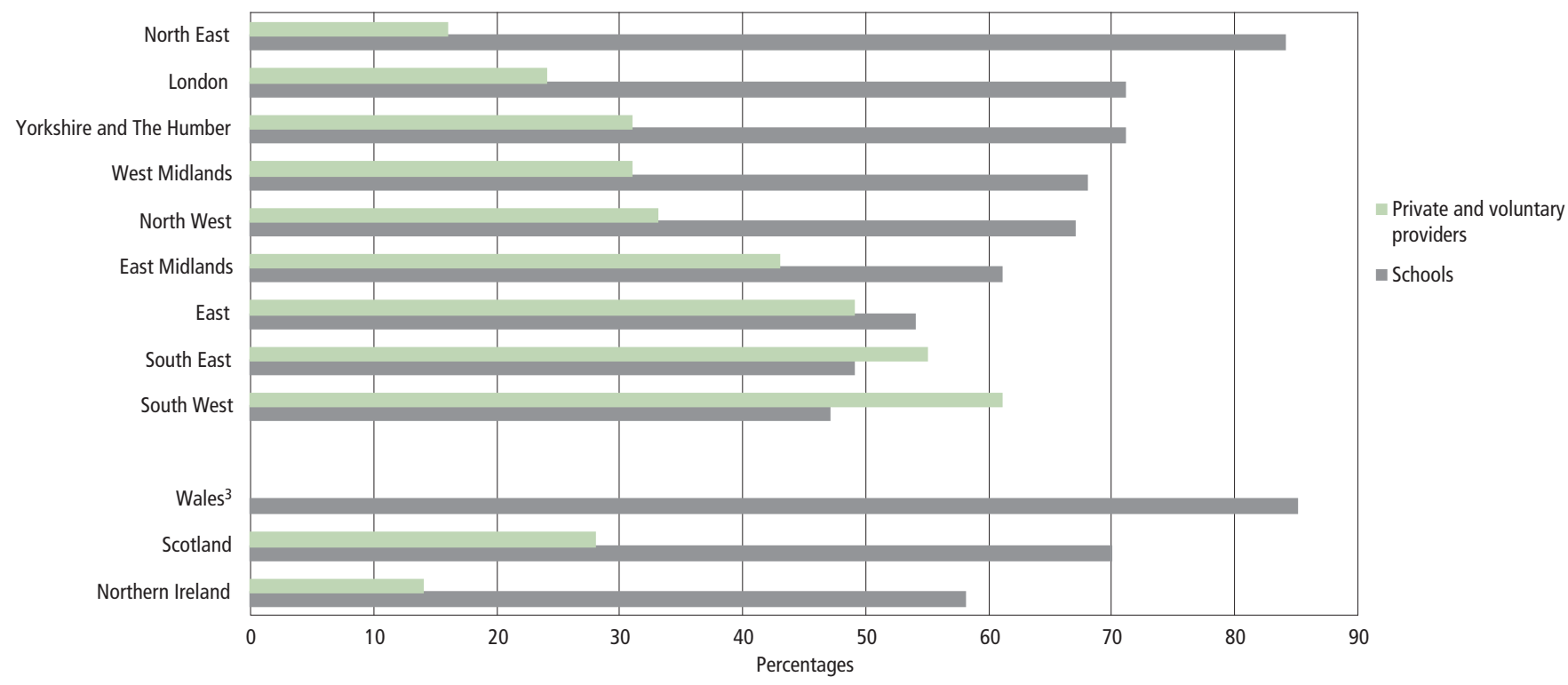

1 Children aged three and four at 31 December. Those in schools may include some two-year-olds.

2 Children may be counted more than once. Types of provision vary between countries. See Box 5 and also Online Table 4.2.

3 There is no information on private and voluntary provision in Wales.

Source: Department for Children, Schools and Families; Welsh Assembly Government; Scottish Government; Northern Ireland Department of Education

were 96 per cent in Northern Ireland and 92 per cent in the South East. The lowest was 87 per cent in Wales.

At KS2 the proportion of a region's pupils reaching national attainment targets in Mathematics was lower in each country and region of England than at KS1. Wales experienced the smallest reduction at 7 per cent, while the English regions dropped by between 10 percentage points (North East and North West) and 14 percentage points (South East).

\section{Secondary education}

Key Stages 3 and 4 in England, Wales and Northern Ireland cover secondary school learning for children aged 11 to 14 and 14 to 16 respectively. There are variations in the curriculum and the way pupils are assessed during KS3 in the three countries, so emphasis here is on attainment at KS4. Key Stage 4 is assessed through GCSEs and equivalent (level 2) examinations generally around age 16 and through National Qualifications, mainly Standard Grades in Scotland.

There were 3.9 million FTE pupils in state-funded secondary schools (including City Technology Colleges and academies in England) in the UK in 2006/07. There was less variation in the percentage of classes with 31 or more pupils at secondary schools than primary (Online table 4.4). All regions of England and Wales had between 6 per cent (South East) and 10 per cent (Wales) of classes exceeding 30 pupils.

In 2006/07, the UK average attainment of five or more $A^{*}$ to $C$ grade GCSE (or equivalent; see Glossary) was 61 per cent. The South East (62 per cent) and Northern Ireland (64 per cent) were the only regions or countries above this threshold, with a further four at 60 per cent or above (East of England, London,
North East, North West). Wales had the lowest KS4 attainment at 54 per cent.

\section{Sub-regional differences}

The regional differences hide larger variations at sub-regional level. This analysis has been done for age-16 attainment but could equally be carried out for other stages. Map 1.15 suggests some patterns in the incidence of high and low level of achievement of 5 or more good grades at GCSE or equivalent (KS4 attainment).

For the regions around London, highest KS4 attainment appeared to be found in local authorities closest to London, while those further away showed lower KS4 attainment. London's highest attainment was found in outer London authorities of Sutton, Redbridge, Bromley, Kingston upon Thames and Barnet (all achieving greater than 70 per cent). A further three were over 65 per cent.

Isolated areas of high attainment (over 65 per cent) were also found in other urban areas in England as well as in some rural areas. For example, such urban areas were found in the South East (Southend on Sea), North East (Gateshead), North West (Trafford, Warrington), Yorkshire and The Humber (Wakefield), West Midlands (Solihull), Northern Ireland (Belfast), and the South West (Bath and North East Somerset, Poole).

In Scotland, Aberdeenshire, East Dunbartonshire, Shetland Islands, Orkney Islands and East Renfrewshire all achieved 65 per cent or more pupils attaining 5 or more Standard Grades at level 1 to 3 and equivalent National Qualifcations in 2006/07. 


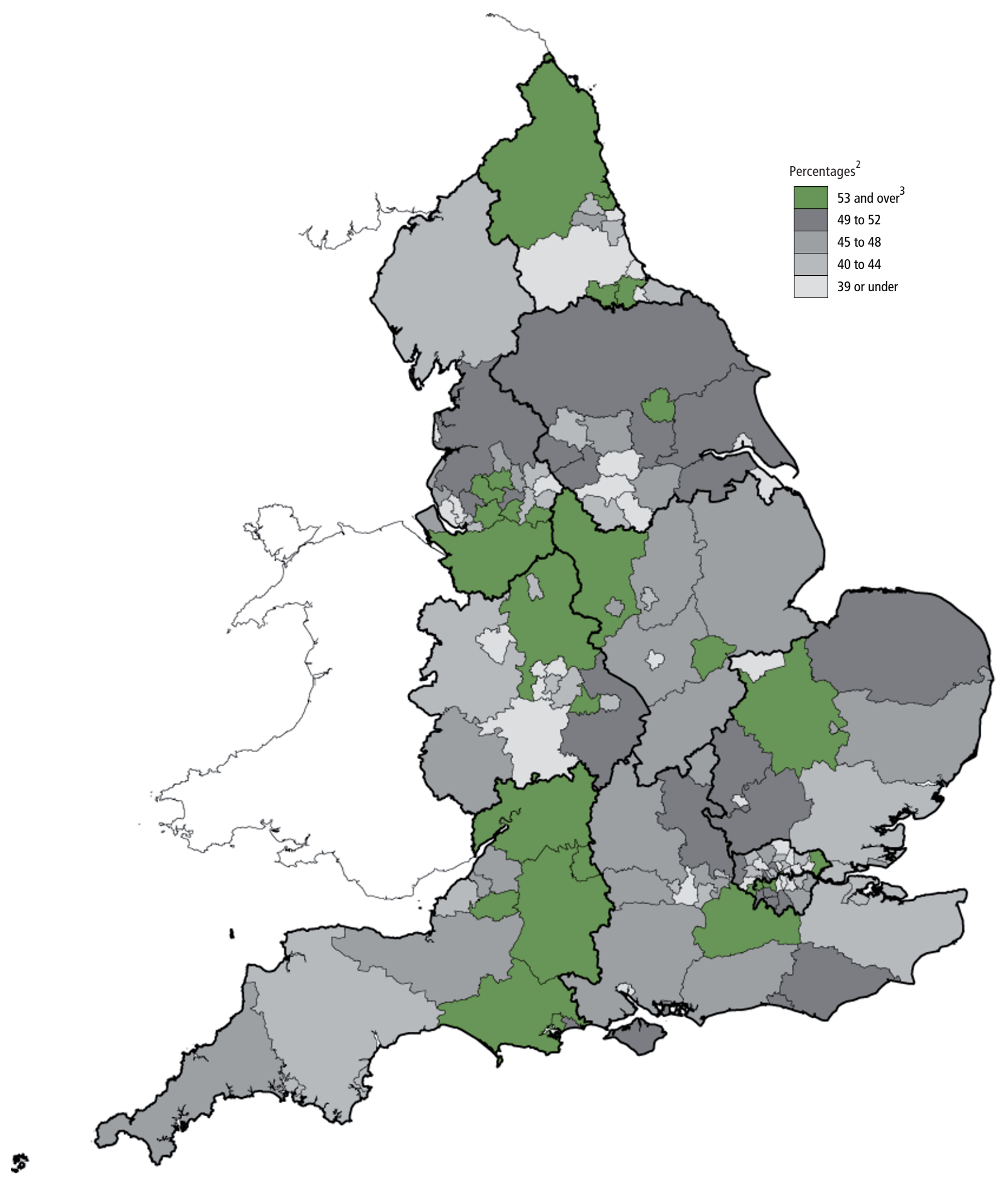

1 Covers children aged 3 to 5 years of age.

2 Percentage of eligible children achieving at least 78 points across the Early Years Foundation Stage with at least 6 in each of the scales in personal, social and emotional development and communication, language and literacy.

353 per cent is the government target.

Source: Department for Children, Schools and Families 
Map 1.15 Pupils' achieving five or more GCSE Grades A $^{*}$-C/Standard Grades 1-3 (or equivalent) ${ }^{2}$, by local education authority, 2006/073

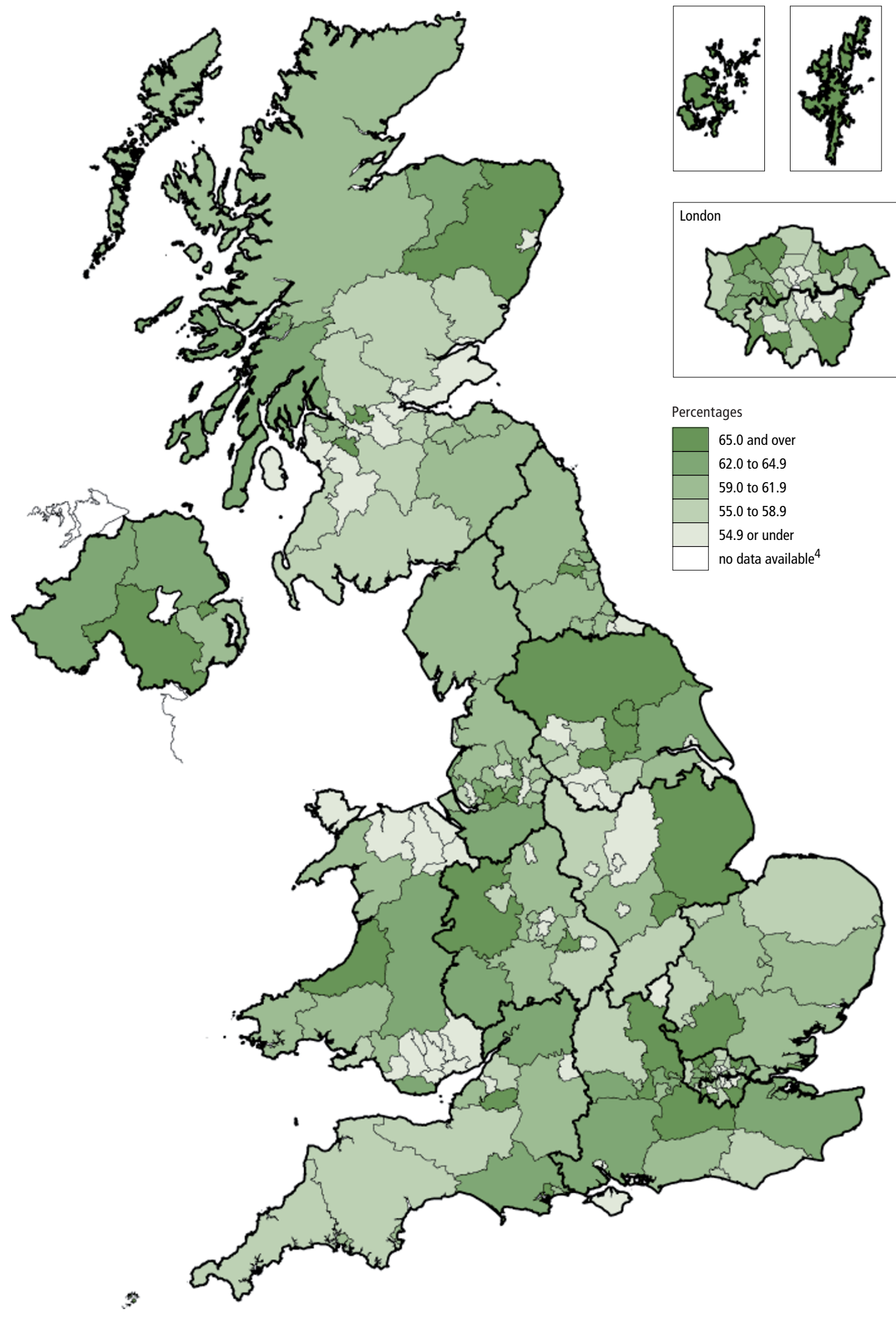

1 See Notes and Definitions for Education and Training online tables.

2 See Glossary.

3 Includes some provisional data.

4 City of London.

Source: Department for Children, Schools and Families; Welsh Assembly Government; Northern Ireland Department of Education 
Map 1.16 Proportion of pupils living in the 20 per cent most deprived ${ }^{1}$ LSOAs, achieving five or more GCSEs ${ }^{2}$ including English and mathematics, by unitary and local authority ${ }^{3}$, 2007

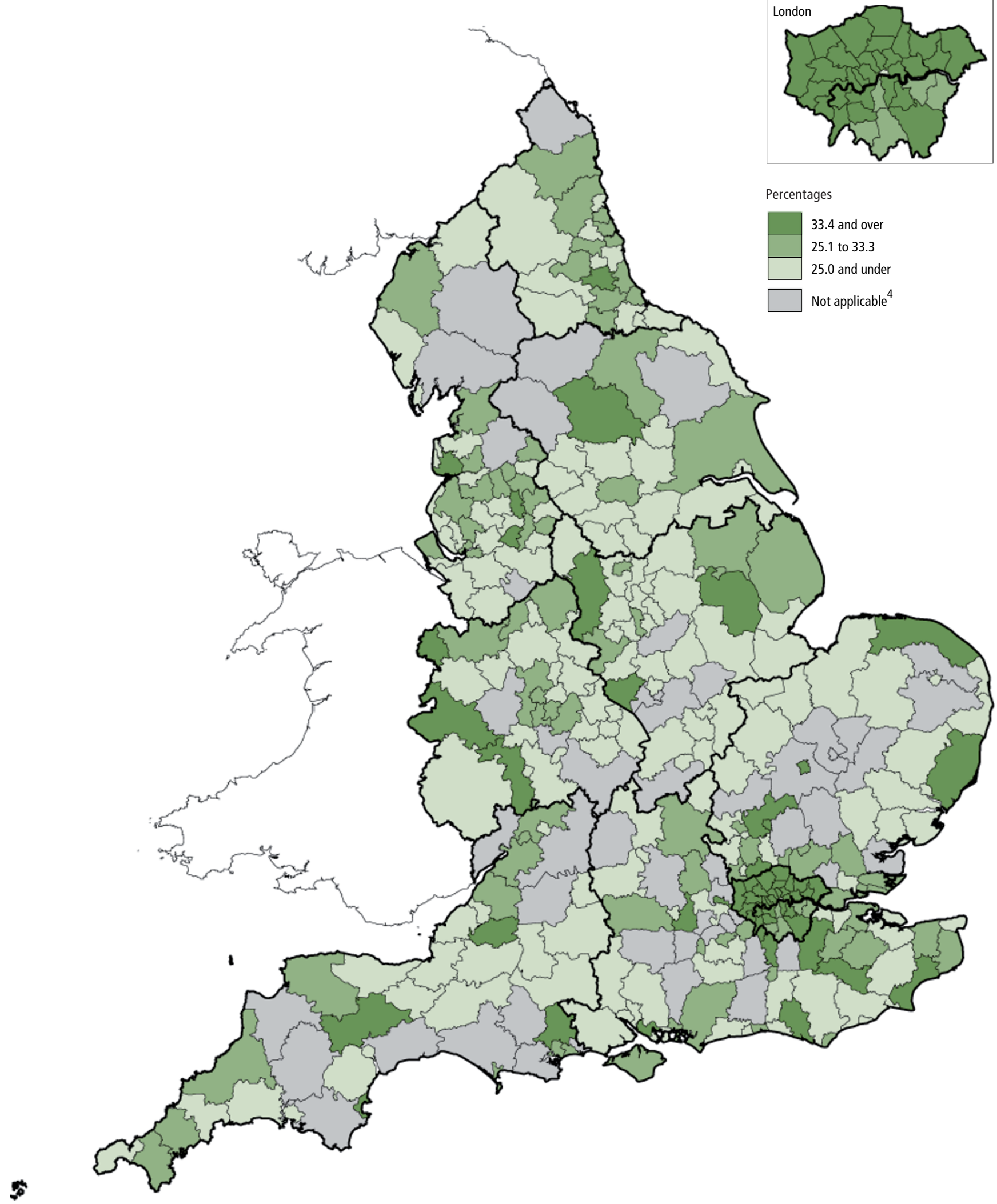

1 Defined by the Income Deprivation Affecting Children Index (IDACI). No comparable data are available for Wales, Scotland and Northern Ireland 2 Or equivalent (see Glossary).

3 Some local authorities may have very small numbers of candidates living in the 20 per cent most deprived LSOAs.

4 Local authorities that do not contain any LSOAs in the most deprived 20 per cent of IDACI. 
Low attainment was seen in parts of London (Greenwich, Islington and Merton were all lower than 50 per cent) and in major urban areas of Yorkshire and The Humber (Sheffield,
Midlands (Derby, Nottingham, Leicester); South Wales valleys, Cardiff, Newport, Glasgow City and Dundee City (all with rates under 55 per cent).

\section{Deprivation and the Rural and Urban Area Classification}

These patterns suggest a possible link to deprivation and the gaps in educational attainment relating to income deprivation and the urban-rural dimension can be explored for England, using IDACI and RUAC. Both are measured in terms of the child's home address.

In England the government target relates to pupils achieving five or more $A^{*}$ to $C$ grade GCSEs (and equivalent) including both English and Mathematics at the end of Key Stage 4. The baseline against which improvement at local level will be measured is 46.3 per cent. In 2007, the proportion of pupils living in the 20 per cent most deprived LSOAs in England who reached the attainment standard was below the target level in all regions. The lowest percentage in any region was 22 per cent in East Midlands, while the highest was 37 per cent in London.

Map 1.16 shows the proportion of pupils achieving five or more $A^{*}$ to $C$ grade GCSEs (or equivalents) including English and Mathematics within England for the 20 per cent most deprived
LSOAs in England (according to IDACI) by local authority district (LAD). Bearing in mind that this excludes some LADs with no very deprived LSOAs and that some LADs included may have only a very small number of LSOAs in the 20 per cent most deprived, eight LADs had pass rates greater than the 2007 national baseline in the most deprived LSOAs. These were spread around the country: Reigate and Banstead (South East), Redbridge (London), South Shropshire and Oswestry (West Midlands), North Kesteven (East Midlands), East Dorset (South West), Suffolk Coastal (East) and Fylde (North West). Nearly seven in ten (243 of 354) local authority districts reported that in their most deprived LSOAs one third or fewer pupils achieved good grades.

The rural-urban character of Key Stage 4 attainment levels is also interesting to investigate. Nationally, 81 per cent of pupils sitting Key Stage 4 examinations lived in Urban areas, with only 10 per cent living in rural Villages, Hamlets \& Isolated Dwellings. The remainder lived in Town and Fringe locations around Urban areas.

Figure 1.17 illustrates the proportion pupils achieving the target of five $A^{*}-C$ GCSEs (or equivalent) including both English and Mathematics by region and a cut-down urban-rural classification. It is evident that Urban areas systematically exhibit the lowest proportion of pupils achieving this level of attainment in all regions, except London where non-Urban areas cover a very small minority of pupils. Apart from this all regions exhibited a trend that the more rural the area, the

\section{Figure 1.17 Key Stage 4 attainment' ${ }^{1}$, by Rural and Urban Area Classification, ${ }^{2}$ England, 2007}

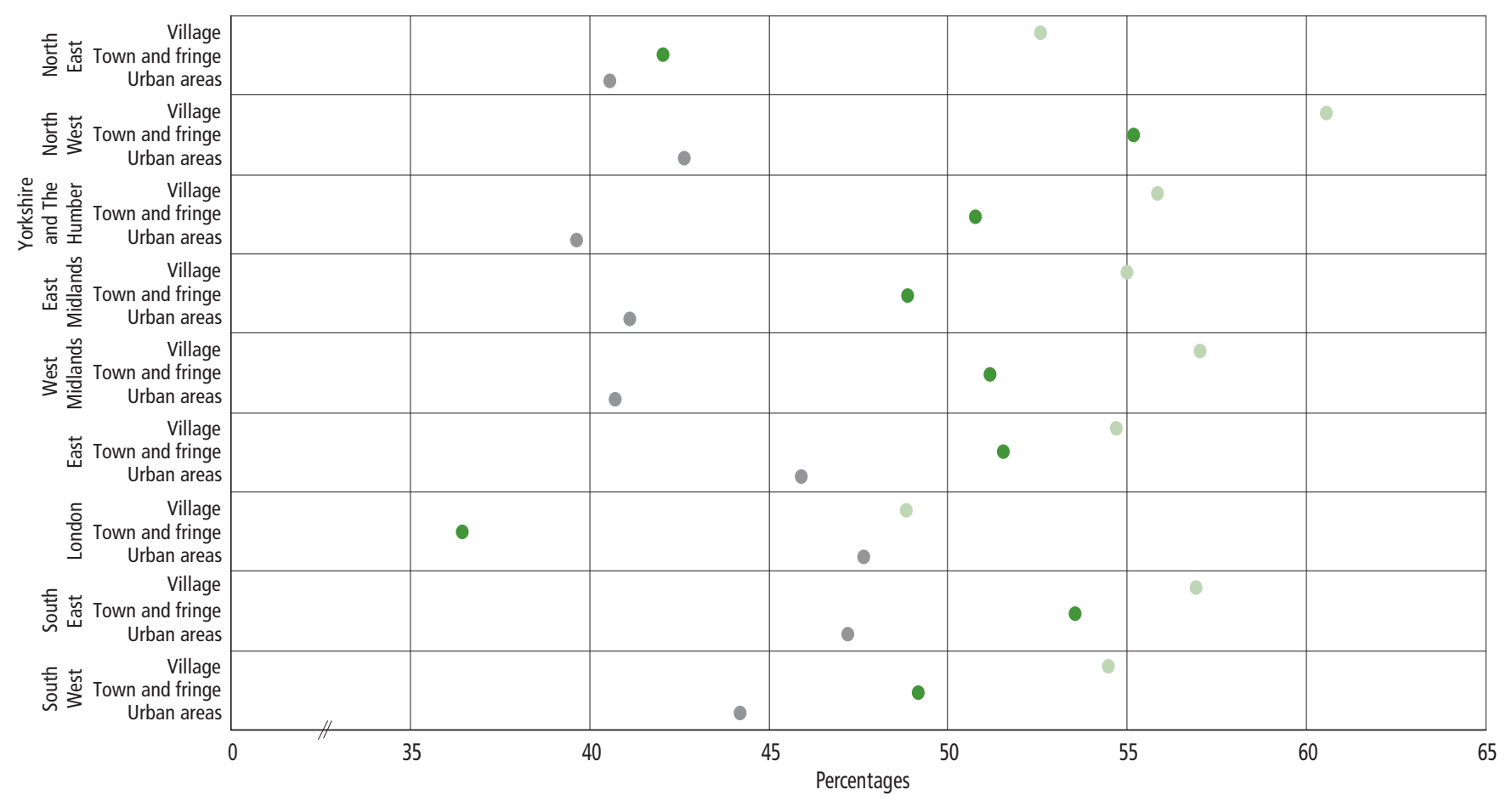

1 Proportion of pupils achieving five or more $A^{*}-C$ (including English and Mathematics). Includes pupils with valid postcodes only.

2 Defined at Census Output Area level based on pupil postcode ('hamlet \& isolated dwelling' has been excluded due to the very small numbers of eligible pupils living in these areas). 
higher the proportion of pupils achieving the attainment standard. The biggest differences between Urban areas and the most rural areas shown in Figure 1.17 were 18 percentage points in North West and 16 percentage points in both West Midlands and Yorkshire and the Humber. The smallest gaps in attainment were found in South East and South West (both 10 percentage points) and East of England (9 percentage points). However, care needs to be taken interpreting these figures because of the relatively small number of pupils living outside Urban areas.

\section{Post-16 education and training}

At the age of 16 it is possible for a young person to leave education, although most go on to one of a number of post-16 opportunities to further their education. These include staying at school, Sixth Form Colleges and Further Education (FE), and eventually Higher Education (for example university), usually at age 18. For those who enter employment there are modern apprenticeships, while Work Based Learning (WBL) programmes are available both inside or outside the workplace. These provide a means for those in the post-16 age group to follow one of four qualification routes: diplomas; general qualifications (A levels and GCSEs); apprenticeships or Foundation Learning Tier. In Scotland, the range of opportunities includes National Qualifications such as
Intermediate 1 and 2, Highers and Advanced Highers. Many go to university in Scotland before age 18 .

Figure 1.18 summarises the variation in the participation of 16 and 17-year-olds in post compulsory education government supported training (GST) for 2006/07 in the countries and regions of the UK (Online table 4.10). This indicates a general trend of participation reducing with age. Lowest participation rates of full-time education and GST for both ages were found in Scotland (79 per cent of 16-year-olds; 45 per cent for 17year-olds) while significantly higher participation at both ages was found in Northern Ireland (95 per cent and 89 per cent). However, it should be noted that, due to differing options available to this age group, inter-country comparisons should be treated with caution (see Notes and Definitions for Online tables). Highest participation rates in England for 16-year-olds were in London (90 per cent), followed by the South East (85 per cent). The England average reduced by 12 percentage points between 16 and 17-year-olds in 2006/07, with the smallest reduction being in London (9 percentage points). The largest reduction was in the North East (13 percentage points).

Full-time education rates were generally higher in the south of England than the north. For participation in Learning and Skills Council (LSC) funded work-based learning (WBL), it was the other way round with the North East having the highest proportion in WBL at 11 per cent (Figure 1.19). Yorkshire and

\section{Figure 1.18 16- and 17-year-olds participating in full-time post-compulsory education and government-supported training, UK' ${ }^{1}, 2006 / 07^{2}$}

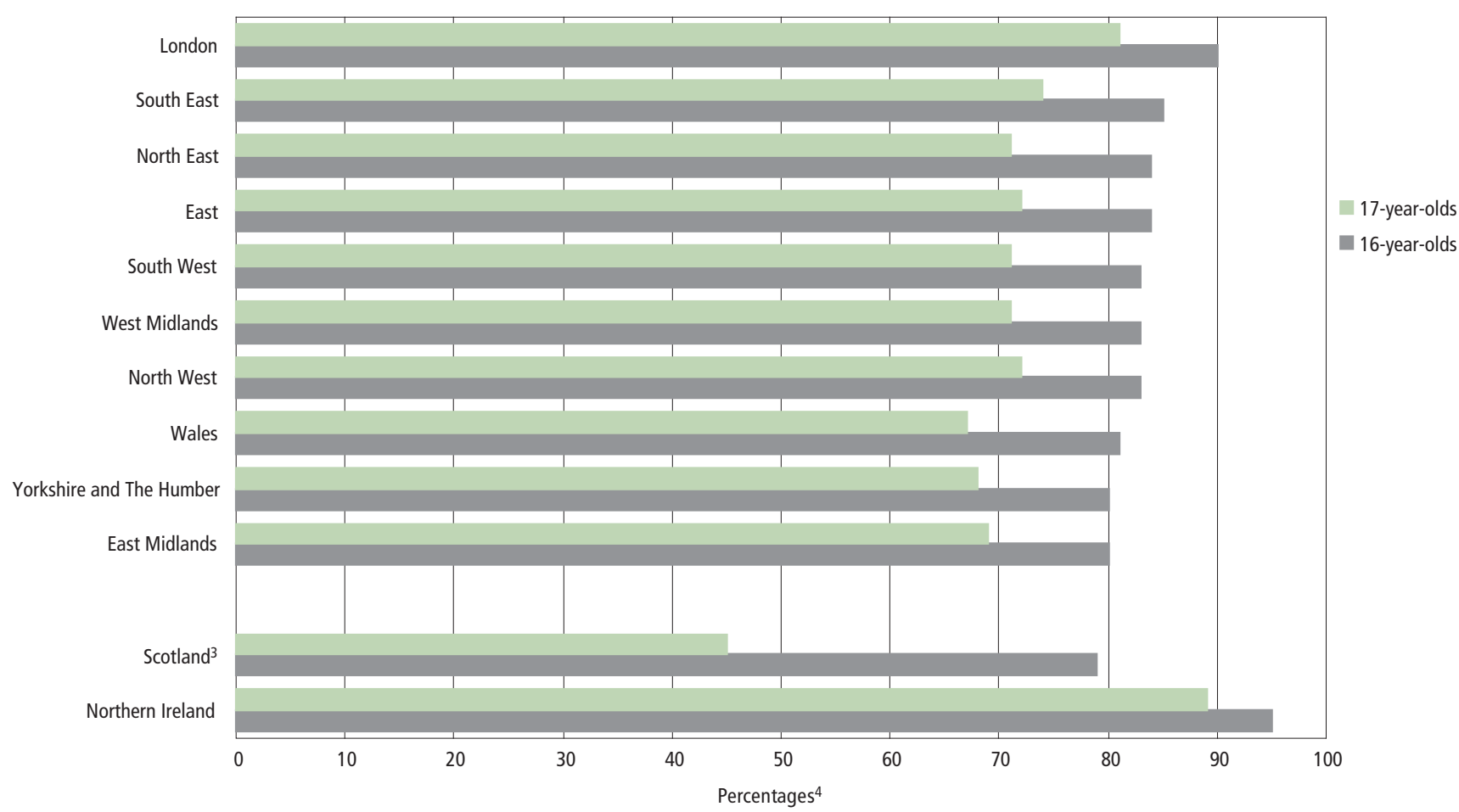

1 Regional figures for England may include a small overlap of young people participating in both full-time education and government-supported training. 2 Provisional.

3 Figures for Scotland exclude 12 per cent of 17-year olds who attend university

4 As a percentage of the estimated 16- and 17-year-old population respectively. 
Figure 1.19 16- and 17-year-olds: participation in education and training by type of institution, England, 2006

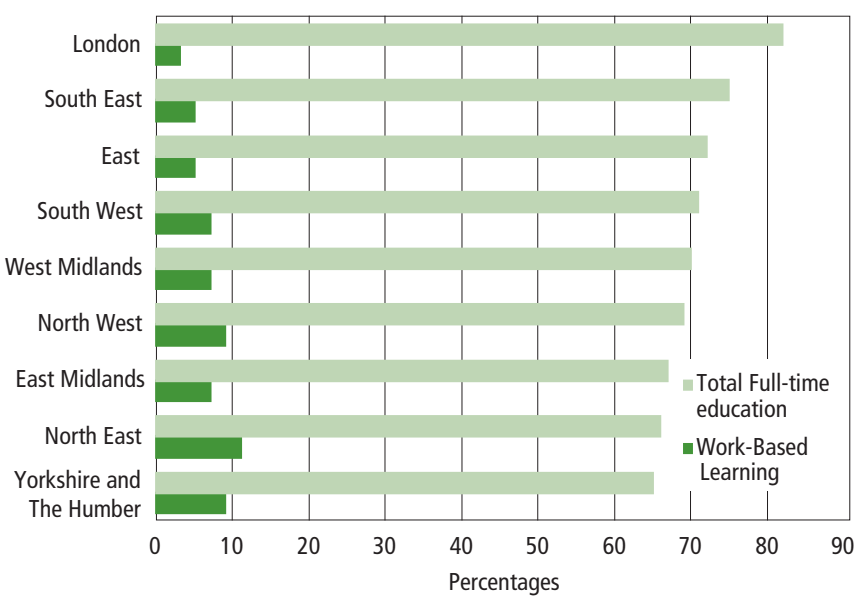

Source: Department for Children, Schools and Families; Welsh Assembly Government; Scottish Government; Northern Ireland Department of Education

The Humber and the North West had the joint second highest participation at 9 per cent. London experienced the lowest rate of WBL participation, with just 3 per cent of 16 and 17-year-olds involved in such training. In contrast; London had the highest rate of participation in full-time education, at 82 per cent, with the South East the next highest at 75 per cent. The lowest participation rates were experienced in Yorkshire and The Humber (65 per cent) and North East (66 per cent).

\section{Box 7 Not in Education, Employment or Training (NEET)}

Information on the number of young people who are not in employment, education or training (NEET) is available from a number of sources. DCSF produces statistics on 16-18-year-olds for England based on a combination of administrative data and survey information although this information is not available by region.

Regional estimates for England are available from Connexions Service administrative data (CCIS) The latest NEET Quarterly Brief from the Connexions Service is at:

www.dcsf.gov.uk/rsgateway/DB/STR/d000751/ NEETQuarterlyBriefQ42008.pdf

Survey information from the Labour Force Survey (LFS) and the Annual Population Survey (APS) can be used to look at the proportion of NEETs in relation to their labour market activity. ONS has recently developed a definition of NEETs using the LFS and APS which provides the most accurate estimate from survey information. Further information on this can be found in the April 2009 edition of Economic and Labour Market Review.

\section{Figure 1.20 Percentage of young people aged 16 and 17 not in employment, education or training (NEET), 2007}

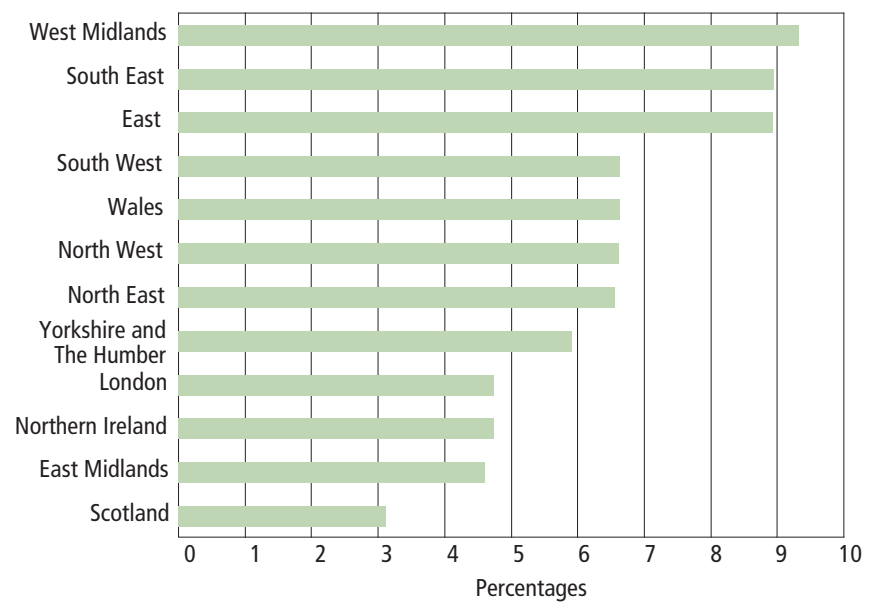

Source: Annual Population Survey, Office for National Statistics

Figure 1.20 shows the proportion of 16- and 17-year-old NEETs at a regional level in 2007 from the Annual Population Survey (see Box 7). The West Midlands, South East and East of England had the highest proportion of NEETs aged 16-17 at 9 per cent each (compared with the UK average of 7 per cent). Scotland had the lowest proportion at 3 per cent, while London, East Midlands and Northern Ireland were also below 5 per cent.

English targets for attainment by age 19 are framed in terms of the percentage of 19-year-olds qualified to at least Level 2 (at least five GCSEs at grades $A^{*}-C$ and equivalents) and Level 3 ( 2 or more $A$ levels and equivalents). Further details of equivalent qualifications are in the Glossary. Map 1.21 summarises Level 2 attainment at regional level in England, and highlights a further apparent disparity between north and south England (Online table 4.15).

Looking at the A level achievement, most English regions were close to the England average figure of 81 per cent of candidates passing 3 or more A-levels or equivalent. However, London and the North East had less than 76 per cent. The proportion was highest in Northern Ireland at 85 per cent, while Wales was the lowest at 71 per cent. (There is no equivalence between Scottish Higher/Advanced Higher examinations and Level 3 qualifications used elsewhere in the UK.)

Pupil absences

Pupil absence from school can have a major impact on attainment. It can be difficult to distinguish between authorised absence (with permission from a teacher or other authorised representative of the school, including illness) and unauthorised absence (including arriving late for school) so overall absenteeism is measured. Pupils in maintained secondary schools in England missed 7.9 per cent of half-day sessions in 2006/07, with Yorkshire and The Humber and North 
Map 1.21 Proportion of 19-year-olds ${ }^{1}$ achieving NVQ Level $2^{2}$, England 2007

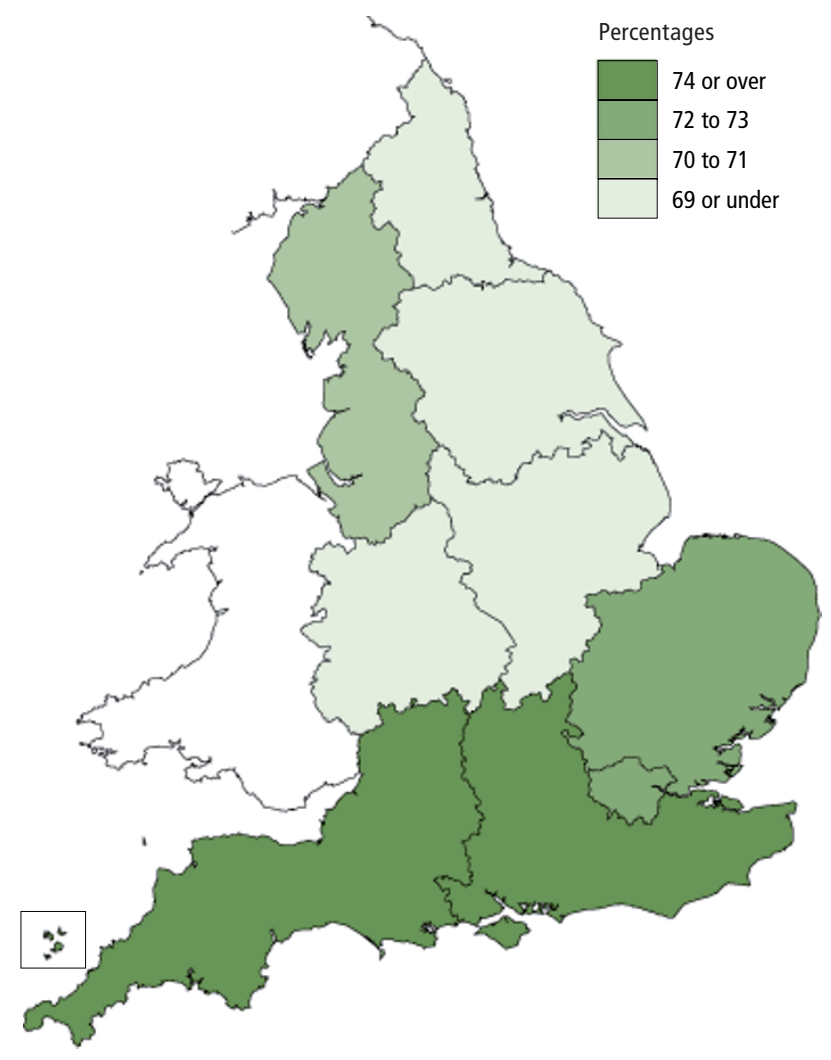

1 Those aged 18 on 31 August 2006.

2 See Glossary.

Source: Department for Children, Schools and Families; Department for Innovation, Universities and Skills

West slightly above this. Wales had a higher rate of overall absenteeism at 9.4 per cent. London and Northern Ireland had the lowest total absence rates at 7.6 per cent of total-half days. Absences in Scotland are reported in terms of days so are not comparable; in secondary schools (excluding year 6) in 2006/07 the overall absence rate was 6.7 per cent.

Despite having the lowest proportion of half-day absences, London was close to the average (6.7 per cent) on persistent absenteeism, that is, the percentage of pupils missing more than 63 sessions (Figure 1.22). The two English regions with highest overall absenteeism (Yorkshire and The Humber and North West) also had the highest persistent absenteeism rates along with the North East (all between 7 and 8 per cent).

\section{Health}

Age-specific death rates provide a single summary set of data on children's health. Infant mortality and low birthweight are indicators of health at the very start of life. But first, this section looks at regional patterns in the topical issues of child obesity and take-up of immunisations. It also considers pregnancies among girls under the age of 18 .

\section{Figure 1.22 Persistent absenteeism in maintained secondary schools, England, 2006/07}

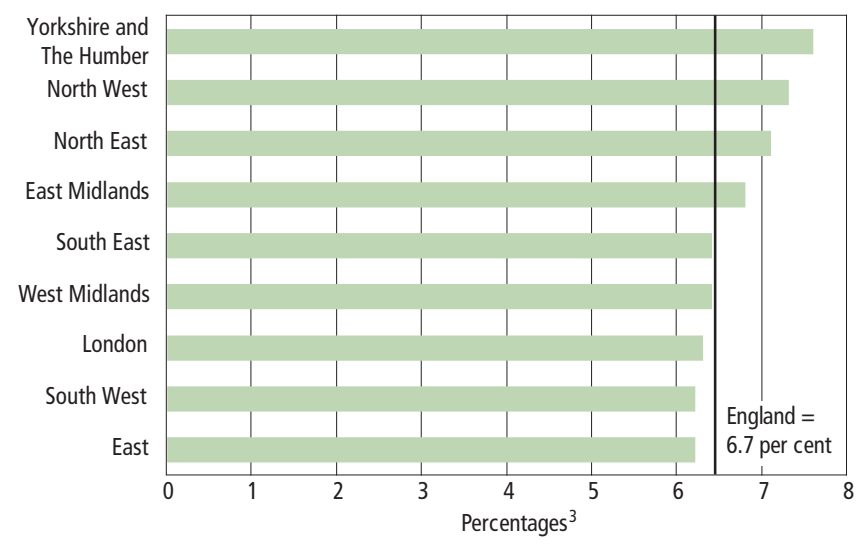

1 Authorised and unauthorised absences (See Notes and Definitions Online).

2 Includes middle schools as deemed. Excludes city technology colleges and academies.

3 Number of pupils that missed more than 63 half-day sessions, expressed as a percentage of the total number of enrolements.

Source: Department for Children, Schools and Families

\section{Immunisation}

\section{Box 8 Immunisations}

Vaccinations are offered to each child based on a strict schedule of primary course and booster shots over the first five years of life, with the majority given within the first year of a child's life.

Main vaccinations are:

- '5 in 1' - includes immunisation against diphtheria, tetanus, pertussis, polio and Haemophilus influenzae type $b$

- MMR - immunisation against measles, mumps and rubella

- Meningitis C

Main vaccinations for ' 5 in 1 ' and MMR are given by the first and second birthday. Take-up rates for the key child immunisations (see Box 8) by the second birthday are shown in Figure 1.23 for Strategic Health Authorities (SHAs) of England (see map on page 173) and countries of the UK.

Uptake of MMR immunisations was consistently the lowest of all vaccinations in all regions and countries. On average 85 per cent of children in the UK reaching their second birthday had received this vaccine. Take up was as high as 92 and 91 per cent for Scotland and Northern Ireland respectively, which were the highest rates within the UK.

In the wake of media coverage detailing possible side effects of MMR, public acceptance of this particular vaccination fell to 80 per cent in England in 2003/04 before increasing steadily to 
Figure 1.23 Children taking key immunisations by their second birthday, UK, 2007/08

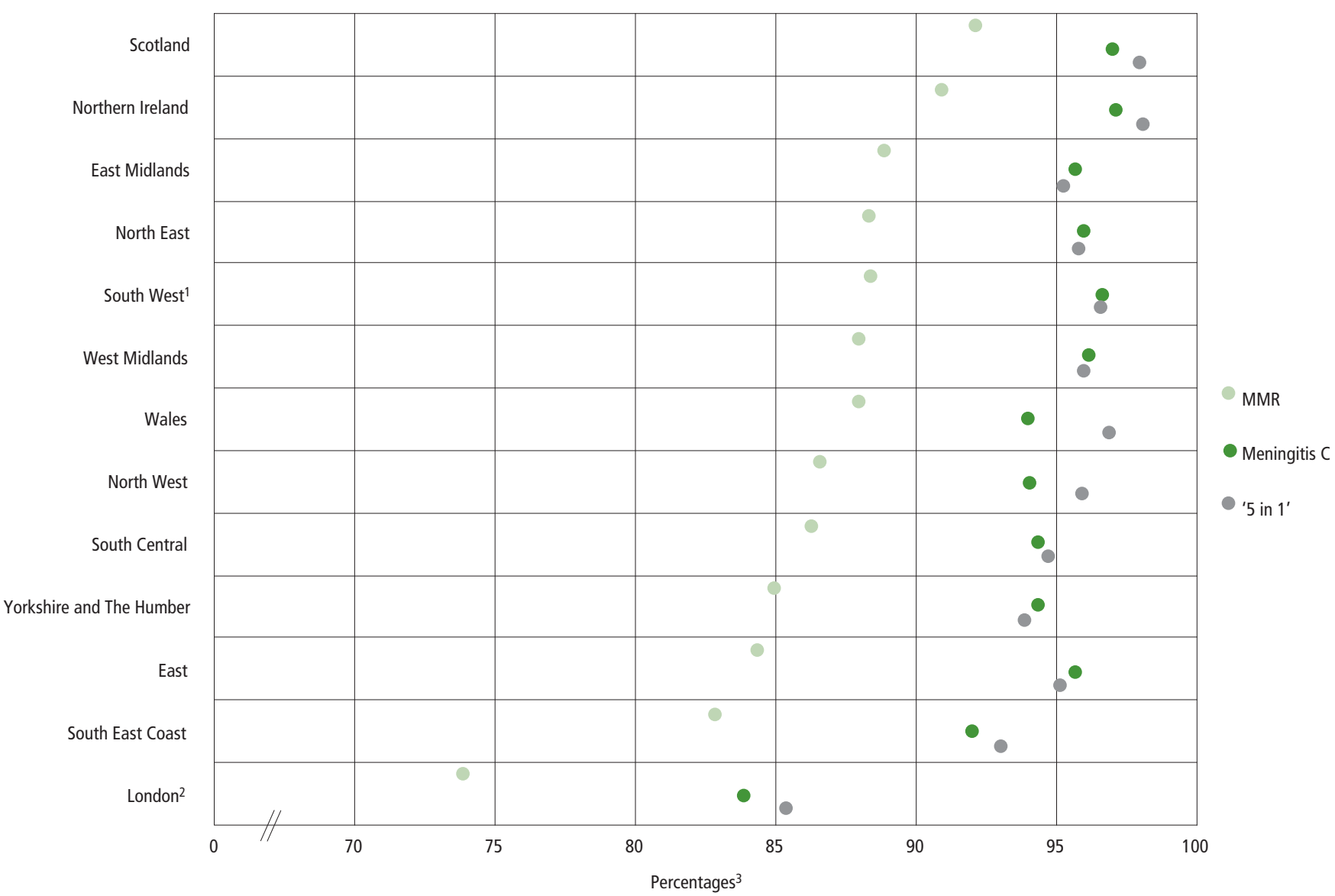

1 One PCT was unable to provide annual data.

2 Six PCTs were unable to provide reliable annual data for any of the key immunisations and one PCT was unable to provide reliable MMR figures.

3 Percentage of eligible children.

Source: The Information Centre for Health and Social Care; National Public Health Service for Wales; Health Protection Scotland; Communicable Disease Surveillance Centre, Northern Ireland

85 per cent in 2006/07 where it remained in 2007/08. This was in contrast to uptake of both ' 5 in 1 ' and Meningitis $C$ that remained between 93 per cent and 94 per cent for the last five years in England.

All ten SHAs reported coverage of MMR vaccine below 90 per cent in 2007/08. For the Primary Care Trusts (PCTs) that provided data, London had significantly lower levels of MMR uptake, at 74 per cent, 9 percentage points lower than the next lowest SHA (South East Coast), and 15 percentage points lower than the highest (East Midlands). However almost a quarter of the 31 London PCTs did not report MMR immunisations in 2007/08

London also experienced the lowest take-up rates for ' 5 in 1' and Meningitis $C$ (averages of 85 and 84 per cent respectively across the 25 PCTs that provided data), followed by South East Coast (around 93 per cent). All other English regions exhibited immunisation rates around 95 per cent for both Meningitis $C$ and ' 5 in 1 ' vaccinations in 2007/08. Scotland and Northern Ireland attained the highest levels of take-up for these vaccinations (both at 98 per cent and 97 per cent for ' 5 in 1' and Meningitis $C$ respectively). Wales also achieved a high rate of 97 per cent for the ' 5 in 1' vaccine.

\section{Obesity}

Being overweight or obese can have serious implications for many aspects of a child's life (such as early onset of breathing difficulties, difficulty in movement, emotional and mental stability, and diabetes).

The variation between regions in obesity prevalence (see Box 9) in Reception Year is small, so Map 1.24 illustrates the local authority rates (Health Boards in Northern Ireland and Council Areas in Scotland - see maps on page 171 and 170 respectively). Obesity prevalence varied by about 10 percentage points between LEAs from 6 per cent in Brighton and Hove to 16 per cent in Hackney. A further 74 LEAs had at least one in ten pupils classed as obese. Map 1.24 shows that many of the high incidences of obesity were found in urban areas including Birmingham, Liverpool, Manchester, Hull, and Newcastle-Upon Tyne, Sunderland, Leeds, Huddersfield, Coventry, Nottingham, Derby, Middlesbrough, Reading, Portsmouth and areas of inner London. 


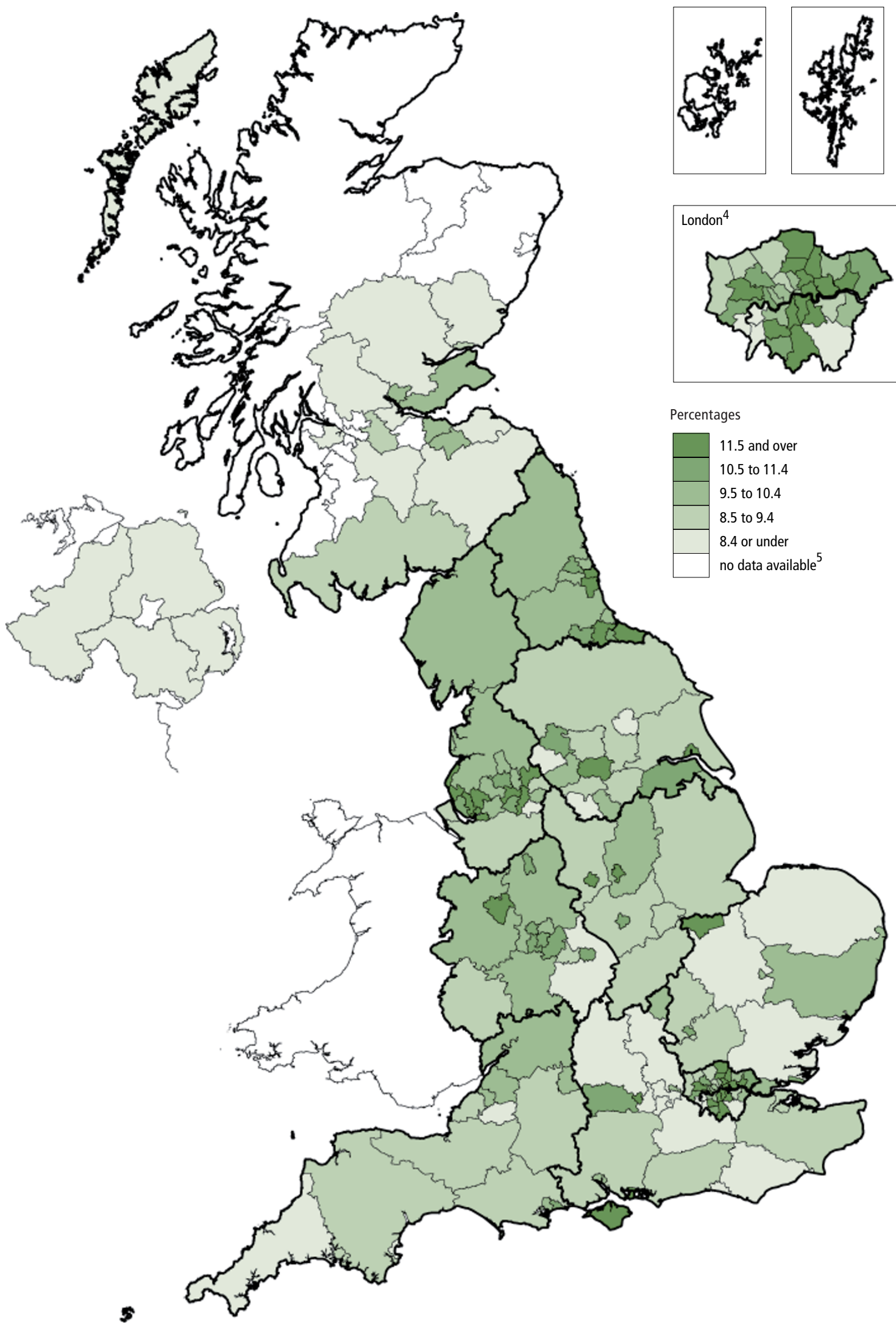

1 Obesity is defined as weight in the greatest 5 per cent of the sample population. See Box 9 .

2 Reception is defined as 4 to 5 years in England, 4 to 6 years in Scotland and 4.5 to 5.5 years in Northern Ireland.

3 By council areas in Scotland and by health and social services boards in Northern Ireland.

4 Data for Westminster and City of London have been merged due to low numbers in the City of London.

5 See Box 9.

Source: The Information Centre for Health and Social Care; Information Services Division, Scotland; Department of Health, Social Services and Public Safety, Northern Ireland 


\section{Table 1.25 Prevalence of obese children in Reception Year': by Rural and Urban Area Classification, England, 2006/07}

Percentages

\begin{tabular}{lr}
\hline Rural and Urban Area Classification & Obesity prevalence \\
\hline Urban $>10,000$ & 10.2 \\
Town and Fringe & 8.5 \\
Village, Hamlet \& Isolated Dwellings & 8.5 \\
England average & 9.9 \\
\hline
\end{tabular}

1 Adapted from The NHS Information Centre 2006/07 NCMP data tables.

\section{Source: The Information Centre for Health and Social Care}

Table 1.25 shows obesity prevalence rates in England by the RUAC and confirms that obesity in young children is most prevalent in Urban areas. There is a high positive relationship between deprivation, using the 2007 Index of Multiple Deprivation, and prevalence of obesity (Department of Health, 2008). That is, children in more deprived areas are more likely to be overweight or obese. This effect was greater in Year 6 than in Reception.

The prevalence of obesity was markedly higher in Year 6 than in Reception for all SHAs in England. This is consistent with the national pattern (9.9 per cent and 17.5 per cent in Reception and Year 6 respectively for boys and girls combined). However, these comparisons may be affected by the differences in participation rates (see Box 9). Bearing this in mind, there are broadly similar geographic patterns for each school year, although the range of variation becomes greater in Year 6 . In particular, London had the biggest difference, with Year 6 obesity prevalence standing at 1 in 5 pupils (21 per cent), 10 percentage points higher than Reception.

Scotland also experienced similar relationship between BMI and levels of deprivation for Primary 1 children (approximately 4 to 6 years-old), in the council areas (see map on page 170) that participated in their national assessment programme (those in the lowlands of Scotland around Glasgow and Edinburgh). Northern Ireland also experienced lowest levels of obesity in Reception Year, at 6 per cent or below of the Reception Year pupil population in all its four health boards. Wales does not currently have a comparable assessment programme (see Box 9).

\section{Box 9 Measuring child obesity}

A child is deemed obese or overweight by determining their Body Mass Index (BMI) from their individual height and weight, and then classifying them against the age and sex-specific UK National BMI percentiles classification, and adjusting this against Cole's IOTF curve. 'Obese' is defined as greater than the 95th percentile, that is the top 5 per cent of the assessed group in a specific year; 'overweight' is defined as greater than or equal to the 85th percentile but less than the 95th percentile.
The National Child Measurement Programme (NCMP) was established in 2005 in England to collect height and weight data for children in Reception (typically aged four to five years) and Year 6 (aged 10 to 11 years). Participation varied significantly between age groups and between LEAs because parents and pupils are able to opt out of the measurement programme. Calculated statistics are heavily dependent upon participation rates, that is, the percentage of eligible pupils who were measured. Therefore it is likely that some results from the NCMP were biased due to underreporting of key pupil sub-groups. Participation rates were higher in Reception than Year 6, with an England mean value of 83 per cent in Reception compared with 78 per cent in Year 6 in 2006/07.

At LEA level the largest difference in participation between age groups was a decrease of 44 percentage points. Large variation in participation was also found within individual school years between LEAs. The lowest participation during Reception was 45 per cent while the highest was 100 per cent; for Year 6 the lowest was 42 per cent and the highest participation was almost 100 per cent.

Data for the devolved administrations are provided from their respective health authorities (Department of Health and Social Services and Public Safety, Northern Ireland; General Register Office of Scotland. Data for Scotland are published on the NHS National Services Scotland Information Services Division's (ISD) website at www.isdscotland.org/child_obesity. The Child Health Systems Programme School System (CHSP-S) from which obesity data are derived, does not have national coverage. For the academic year 2006/07, the BMI statistics cover approximately 78 per cent of children in Primary 1 among the nine participating NHS Boards, and approximately 48 per cent of children in Primary 1 across Scotland. Council areas covering the highlands and islands of Scotland (for example Highland, Argyll \& Bute, Moray and Aberdeenshire) did not participate in the current assessment, and will be introduced later in a phased assessment programme of childhood obesity. Data for Northern Ireland are available at: www.ninis.nisra.gov.uk/mapxtreme/DataCatalogue. asp? button $=$ Health .

Wales does not currently have a comparable assessment programme. The Welsh Assembly Government has requested the National Public Health Service for Wales and other partner organisations to co-ordinate a study to examine how a national height and weight measuring programme for primary school children could be introduced in Wales that would be consistent with results from England's National Child Monitoring Programme. More information may be found at: www. wales.nhs.uk/sites3/page. $\mathrm{cfm}$ ? orgld=719\&pid=34804. 


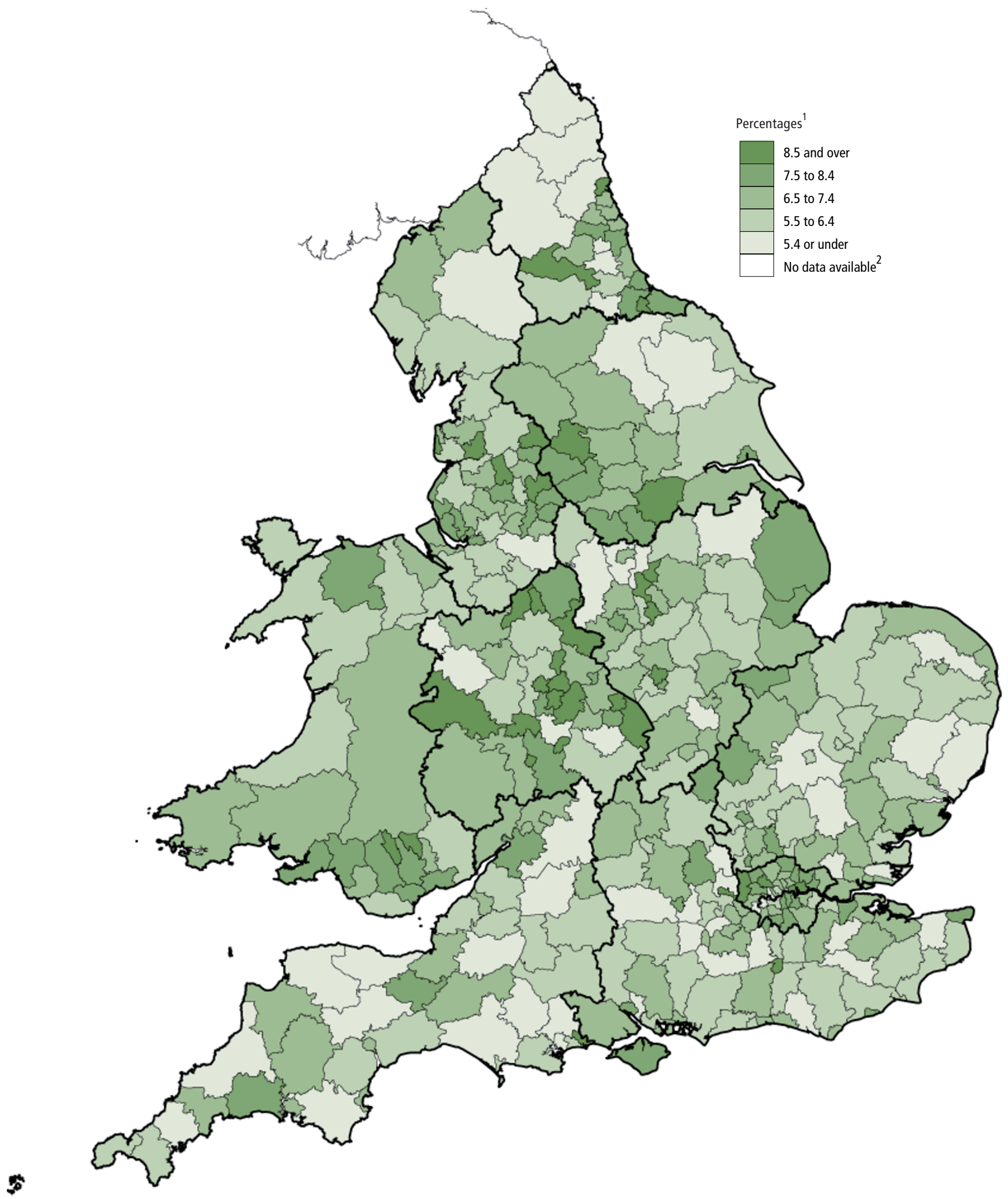

1 Number of live births under $2.5 \mathrm{~kg}$ as a percentage of all live births for which the birthweight is known

2 City of London and Isles of Scilly.

Source: Office for National Statistics 


\section{Low weight live births}

Recent research ${ }^{2}$ found that low birth weights were one contributing factor leading to poor health, poor development and low educational attainment in children. Babies born at low weights are at higher risk of dying in the first few months of life.

Variations in the proportion of live births less than $2.5 \mathrm{~kg}$ (that is, low weight live births) at regional level for 2007 (Online table 6.2) show a familiar pattern with some of the most urbanised regions having the highest proportions - West Midlands (8.5 per cent of live births), Yorkshire and The Humber (7.8 per cent) and London (7.5 per cent). Map 1.26 shows the data at local authority level for England and Wales, confirming this trend.

\section{Childhood mortality}

Deaths among children (whether from natural causes or accident) are relatively infrequent, although infant mortality is still relatively high compared with other childhood age groups (Online table 10.10).

The age-specific death rate for the under-ones is highest in the Midlands and north of England. The West Midlands (5.9 deaths of infants under one year of age per 1,000 population of the age group) and Yorkshire and The Humber (5.6) were the regions with the highest ratesin 2007. The UK average was 4.8 per 1,000 but for the one to four age group it dropped to just 0.2 per 1,000 population in the age group, with Yorkshire and The Humber, North West and West Midlands above the UK average at 0.3 per 1,000 population. Death rates over the five to 15 years age interval were fairly consistent across the whole of the UK at 0.1 deaths per 1,000 population of that age group, although North East peaks at 0.2 deaths per 1,000.

Infant mortality rates (the number of deaths of infants under one year of age per 1,000 live births) are shown in Figure 1.27 for 2007 (Online table 6.3). Again, West Midlands (5.9 infant deaths under 1 year of age per 1,000 live births) and Yorkshire and The Humber (5.6) had the highest values.

\section{Conceptions to under-18s}

Teenage mothers may suffer disruption to their education, which may have consequences for the wellbeing of both mother and child in subsequent years. Figure 1.28 illustrates (black line) variation in the rate of conceptions to under-18s for the regions of England and for Wales in 2006 (Online table 10.12). Bars indicate the percentages of these conceptions that lead to either a maternity or an abortion.

The northern regions, West Midlands, London and Wales had conception rates higher than the England and Wales average of 41 per 1,000 young women aged 15 to 17. Lowest rates were in the East, South East and South West.

In all regions except for London, conceptions to under-18s were as likely or more likely to result in a maternity as an abortion. In

2 National Foundation of Education Research (NFER), see www.nfer.ac.ukl research-areas/pims-data/outlines/narrowing-the-gap-in-outcomes.cfm)

\section{Figure 1.27 Infant mortality ${ }^{1}, 2007$}

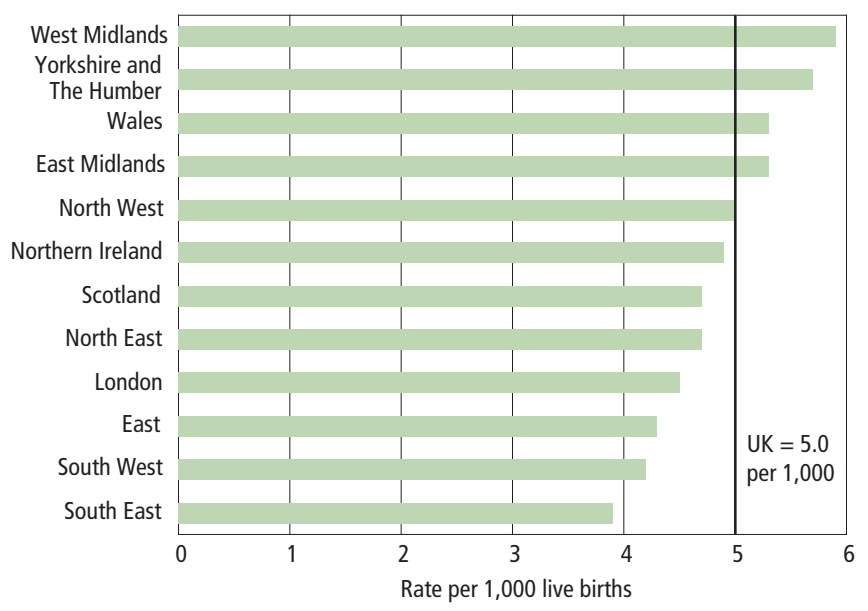

1 Deaths of infants under one year of age per 1,000 live births. See Online Notes and Definitions.

Source: Office for National Statistics; General Register Office for Scotland; Northern Ireland Statistics and Research Agency

London 61 per cent of conceptions led to an abortion. The South East, East of England and South West experienced an almost equal division between the two outcomes. North East, Wales, Yorkshire and The Humber and the East Midlands each experienced over 55 per cent of conceptions leading to a maternity.

\section{Care}

\section{Social care of children}

There were 60,000 children in care in England in the year to 31 March 2006 (Online table 6.18). This comprised 55 per 10,000 of the resident population aged under 18 . The highest regional proportion in England was the North West (67 per 10,000 resident population), followed by London (73 per 10,000). The lowest regional rates were the South East and East Midlands (42 and 39 per 10,000 respectively). The figure for Wales was 70 per 10,000.

Northern Ireland (56 per 10,000) had a similar rate of children in local authority care to the England average. Scotland had a much higher rate (116 per 10,000 resident population) but this is because children who are subject to a supervision requirement with no condition of residence and, therefore, remain at their normal place of residence (often the family home) are included in the statistics (see Notes and Definitions for Online tables and Box 10).

Fostering is the most usual way of caring for children in care in England, Wales and Northern Ireland. North East and Wales (both 74 per cent), South West (73 per cent) and East (72 per cent) all had higher percentages than the England average of 70 per cent. North West (67 per cent) and Northern Ireland (63 per cent) had the lowest proportions of children in care placed in foster homes. London and Northern Ireland had the highest proportions of these children in homes and hostels at 13 per cent (Figure 1.29). 
Figure 1.28 Conceptions ${ }^{1}$ to women aged under 18: by outcome, England and Wales, 2006

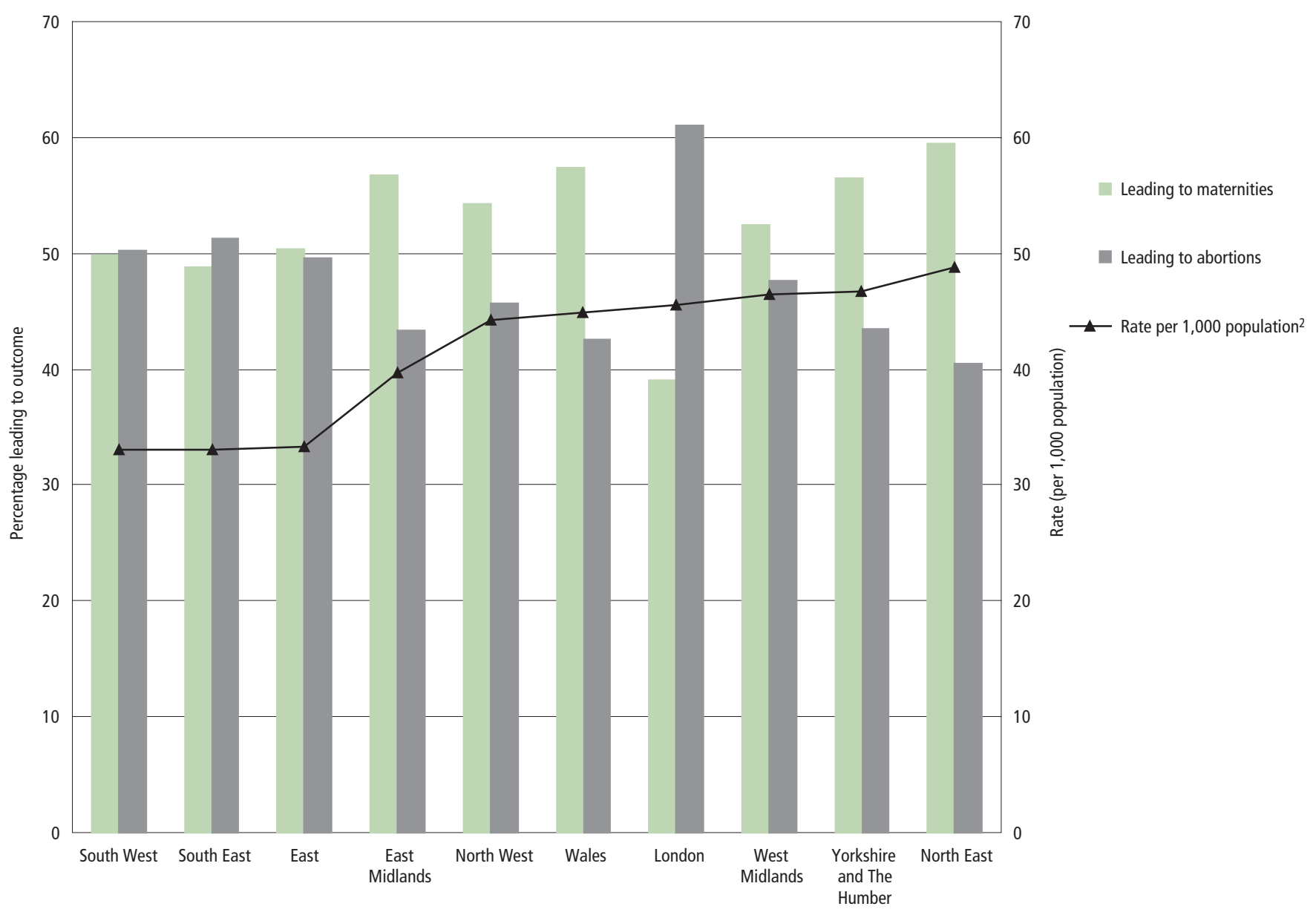

1 See Online Notes and Definitions.

2 Based on the population of women aged 15 to 17.

Source: Office for National Statistics

\section{Child Protection}

\section{Box 10 Child protection}

\section{Child Protection Plans}

Children in England and Wales who local authorities consider may need to come under their care will initially be put through two phases of assessment by social services. This will determine the most suitable course of action, which is contained in a Child Protection Plan (CPP).

\section{Children's Hearing System}

In Scotland, young people up to the age of 16 are dealt with through the Children's Hearing System, which is a unique system which deals with the care, protection, guidance and control of children. Children may be referred to the system if they have suffered abuse or neglect or if they are the perpetrator of an offence. A range of statistics are available from the Scottish Children's Reporter Administration (see References).
In England 34,000 Child Protection Plans (see Box 10) commenced in 2007/08, and in Wales almost 3,000. In Scotland 2,800 children were registered on child protection registers.

Figure 1.30 illustrates the regional incidence of CPPs in England in terms of rates per 10,000 population in the age band. The North East had the highest rate of children becoming subject to a CPP in all three age groups considered, with 74 per 10,000 population in the under fives, dropping to 29 per 10,000 population in the 10 to 15 age band.

Children aged under five were the age group most likely to become subject to new CPPs in all regions of England. After the North East, the West Midlands and East of England were the only others at 60 per 10,000 population or greater. South East, London and East Midlands had the lowest rates in this age group at 42 or fewer per 10,000 of the population.

Similar regional patterns were also seen in the other age bands, except for London. London experienced much greater incidence rates of children becoming subject to CPPs in the five to nine and 10 to 15 age groups, with 35 and 27 respectively in 
Figure 1.29 Children looked after by local authorities ${ }^{1,2}, 2006^{3}$

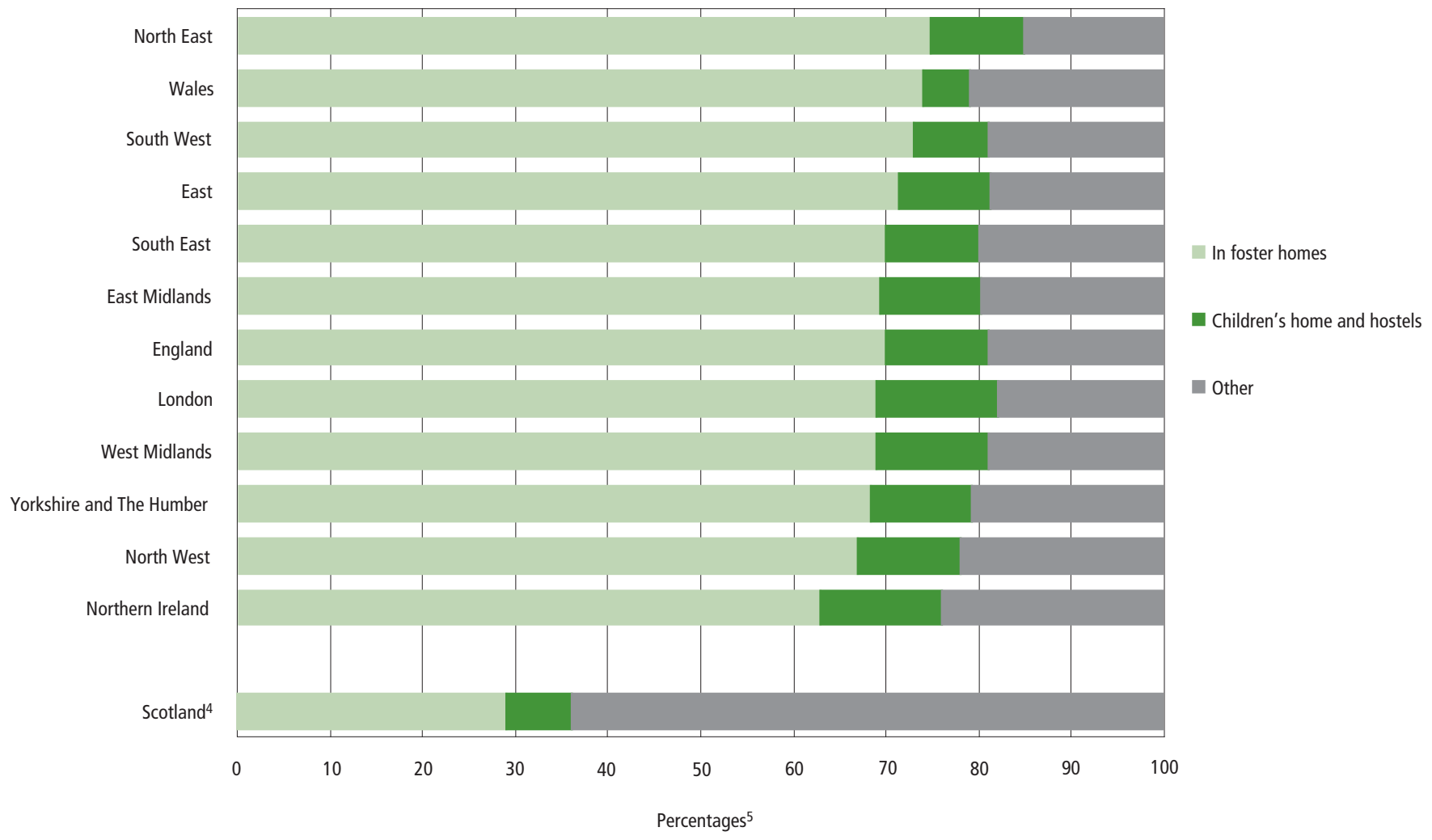

1 Figures exclude children looked after under an agreed series of short-term placements.

2 For definition see Online Notes and Defintions.

3 Year ending 31 March 2006.

4 Scotland has a different definition of looked after children, so data are not directly comparable with the rest of the UK.

See Online Notes and Definitions for Health and Care.

5 Percentage of total children looked after by local authority.

Source: Department for Children, Schools and Families; Local Government Data Unit Wales; Scottish Government Education Department; Department of Health, Social Services and Public Safety, Northern Ireland

every 10,000 children in each age group. Whereas it was ranked second lowest of all regions in the 0-4 group, London was ranked third and second highest respectively in the 5-9 and $10-15$ age groups.

\section{Crime and Justice}

In England, Wales and Northern Ireland statistics on sentencing at magistrates' courts and the Crown Court provide a measure of criminal activity among young people between the ages of 10 and 17. At the age of 18 juveniles become young adults in the eyes of the law. The legal system in Scotland differs from that in the rest of the UK: eight years is the age of criminal responsibility. In Scotland, young people up to the age of 16 are dealt with through the Children's Hearing System (see Box 10).

To put youth offending into perspective, the average offending rate for indictable offences in the full population of England and Wales in 2006 was 1,065 per 100,000 of the population. The peak age for known offending in England and Wales varies for males and females; for males this was at 17 years old with approximately 6,100 found guilty per 100,000 of the population, and at 15 years of age for females with 2,200 persons found guilty per 100,000 of the population.

In England and Wales, younger offenders may initially receive a juvenile reprimand, final warnings, caution or, if aged 16 or older, a penalty notice for disorders (PND) by the police as a pre-court diversion. If their offence needs court consideration, they will generally attend the youth court (magistrates' court). Here they may be acquitted, or receive one of a number of sentences or orders which may take the form of a referral, curfew, caution, conviction, have their offence taken into consideration by courts (TIC) or Detention Training Orders (DTOs). These 'disposals' will depend on the crime committed and offending history of the individual concerned. Appearances at the Crown Court are reserved for more serious (indictable) offences or defendants' second or subsequent appearances. For more details, see Sentencing Statistics, 2007 England and Wales, (Ministry of Justice, 2007).

Proceedings and trials at court

During 2007 in England and Wales 67,000 young offenders were proceeded against in the magistrates' courts, with a further 3,500 sent for trial in the Crown Court. In Northern 
Figure 1.30 Rates of children' becoming subject ${ }^{2}$ to a Child Protection Plan in England, 2008

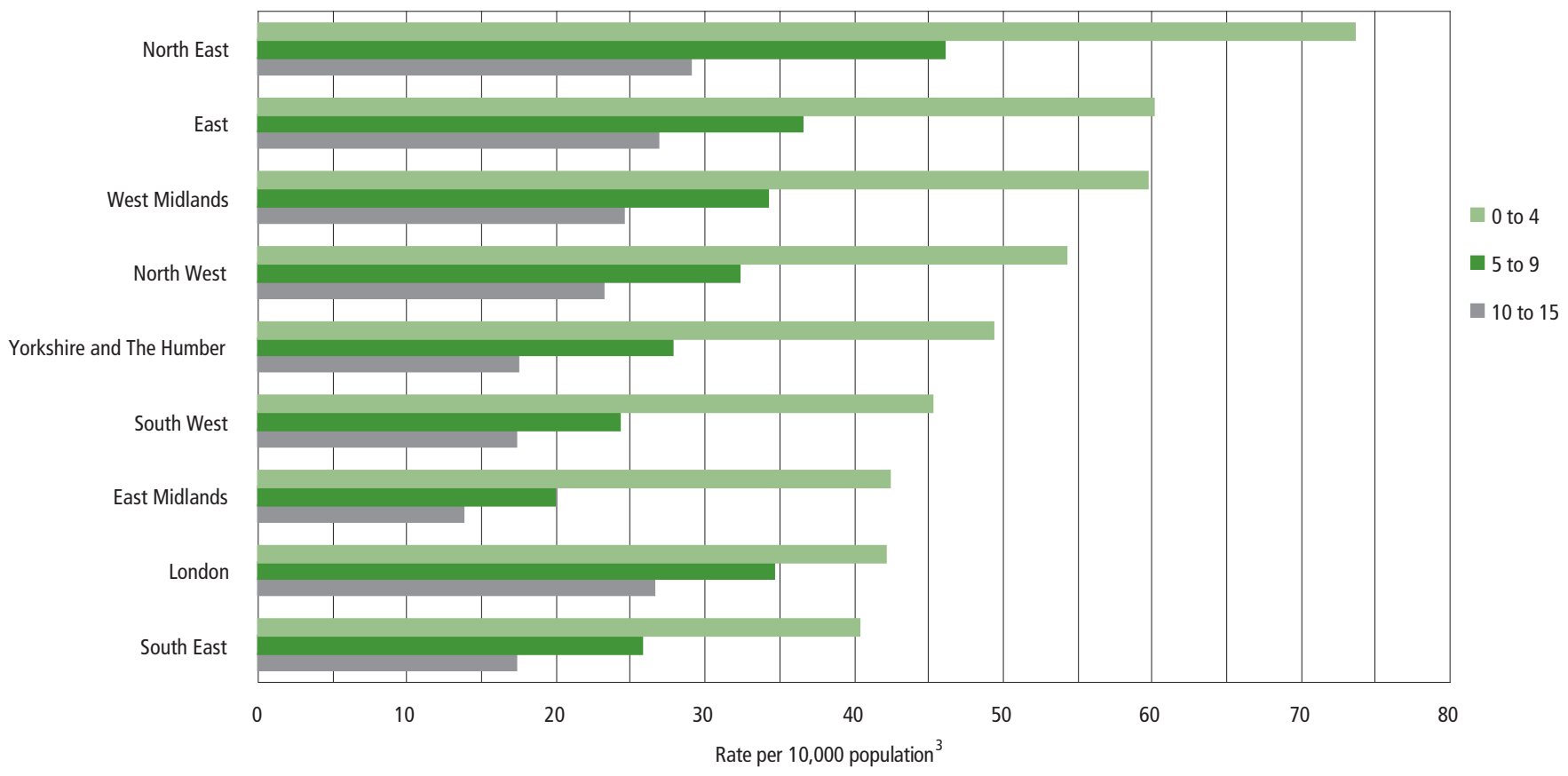

1 Where a child was made the subject of a Child Protection Plan more than once in the year within the same authority, each occasion has been counted.

2 Including unborn children.

3 Estimated using age-specific 2007 mid-year population estimates.

Source: Department for Children, Schools and Families, Office for National Statistics

Figure 1.31 Attendance rates of 10 to 17-year-olds at magistrates' courts and the Crown Court, England and Wales, 2007

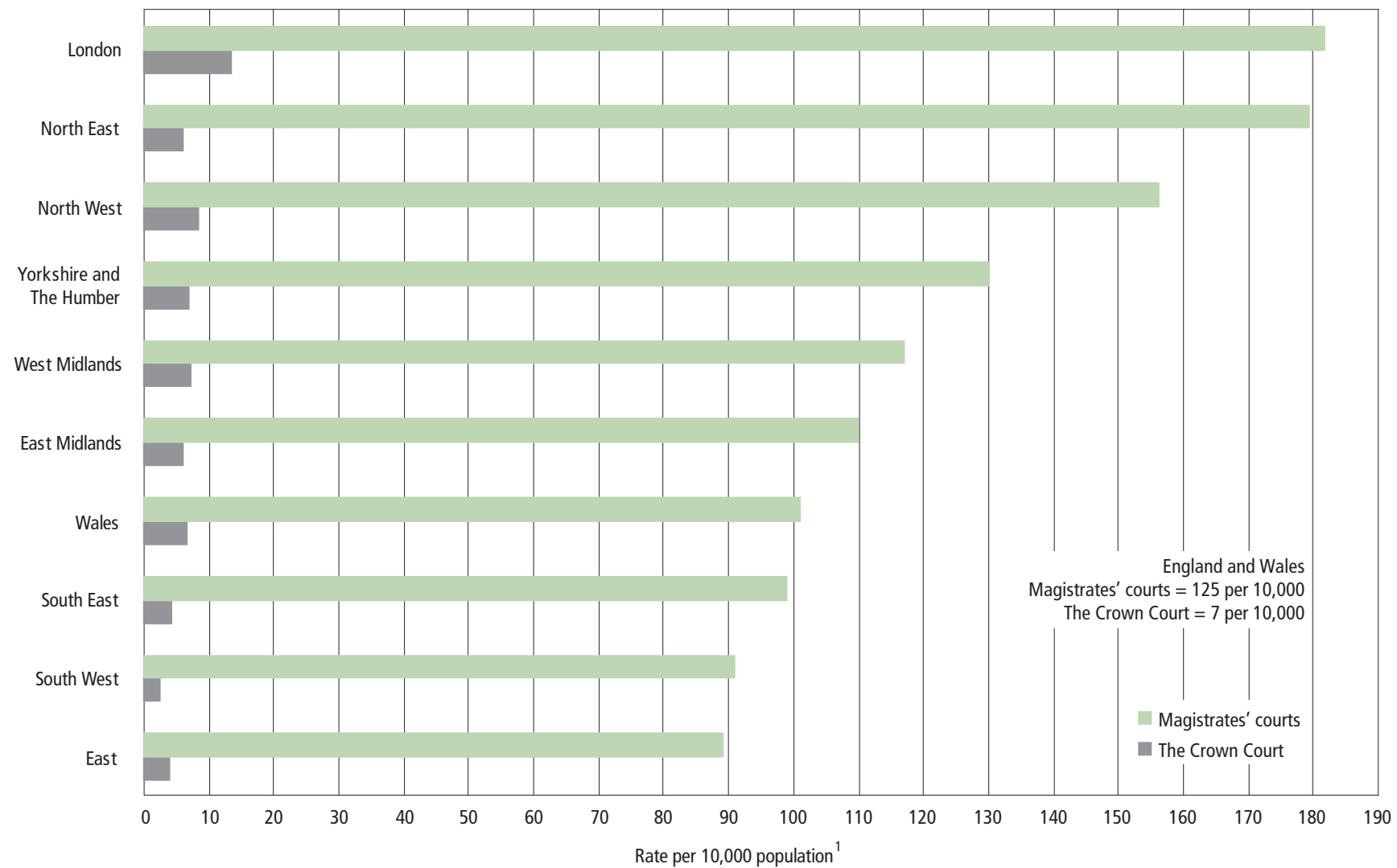

1 Estimated for 10-17-year-olds using 2007 mid-year estimates. 
Ireland 3,300 youth defendants were dealt with in the Magistrates' Court or Crown Court. Figure 1.31 illustrates the rates of 10 to 17-year-olds that were considered at magistrates' courts or at the Crown Court in England and Wales. East of England had the lowest rate of children being proceeded against at magistrates' courts, at 89 per 10,000 of the 10-17 population. This region, along with South West (91) and South East (99) were the only regions with rates below 100 per 10,000 of the 10-17 population. The highest rates were found in London (182), North East (179) and North West (156 per 10,000 of the $10-17$ population).

Map 1.32 illustrates the variation in rates of those proceeded against in magistrates' courts only, per 1,000 10 to 17-year old population, for each Police Force Area (PFA - see map on page 172 ) in England and Wales. Highest rates of defendants appearing at magistrate' courts were in Northumbria (20 per 1,000 of the 10 to 17-year old population), followed by Greater Manchester, Durham and Greater London (Metropolitan and City of London PFAs), all at 18 per 1,000.

\section{Court sentencing}

Sentences given to children and young people are more likely to be small, for the first offence at least, and could involve

\section{Map 1.32 Proceedings against 10 to 17- year-olds at magistrates' courts by Police Force Area ${ }^{2}$, England and Wales, 2007}

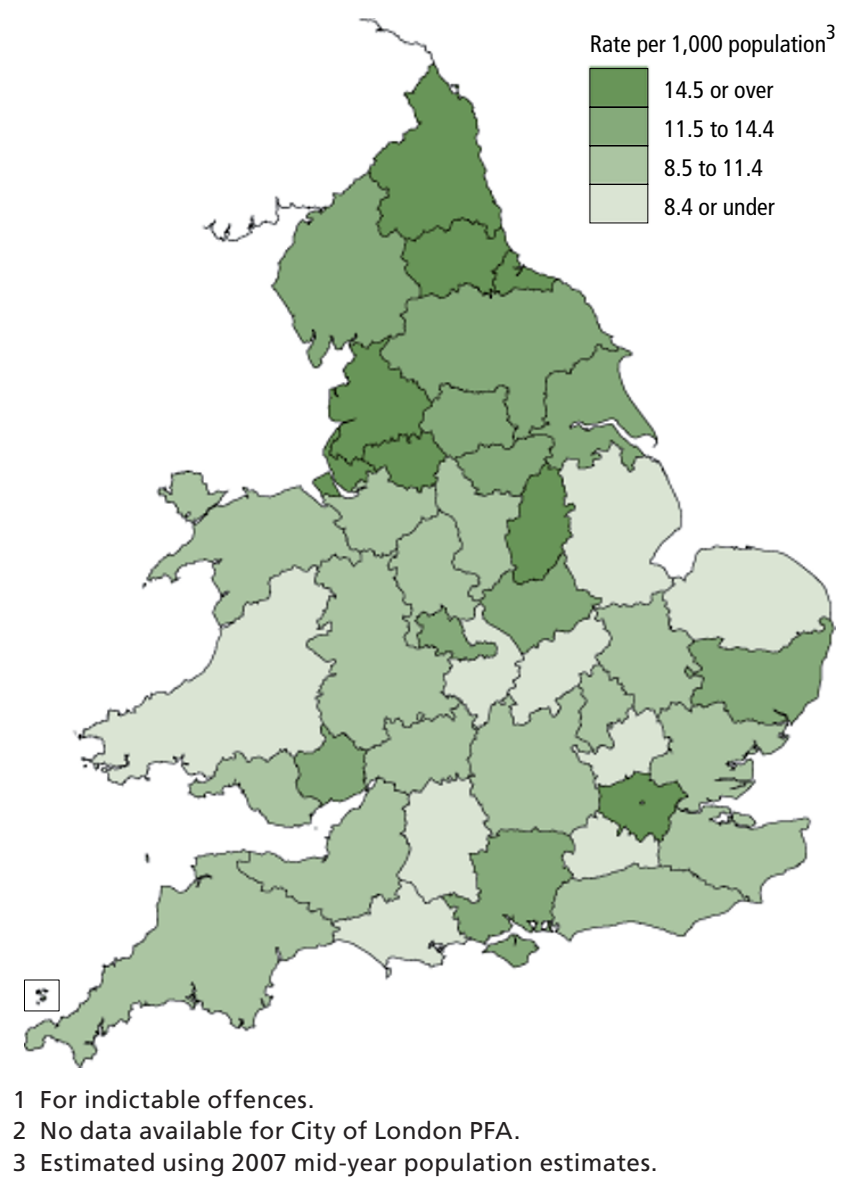

Source: Ministry of Justice, Office for National Statistics

\section{Figure 1.33 Proportion of sentenced 10 to 17- year-olds given community sentences, England and Wales, 2007}

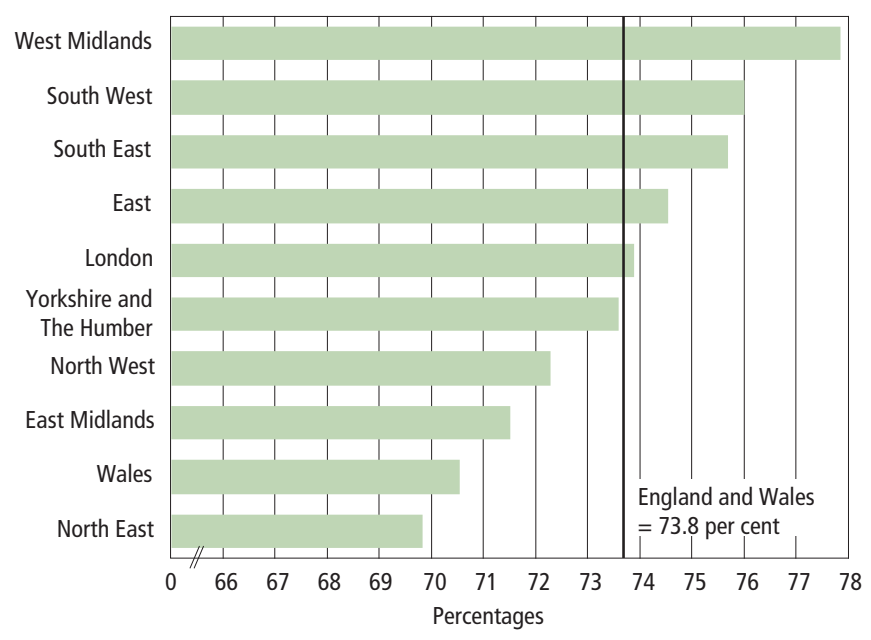

Source: Ministry of Justice

types of referral, training or community service. The most frequent is the community sentence.

Figure 1.33 illustrates the variation between the regions of England and in Wales in the number of community sentences issued to 10 to 17-year-olds as a percentage of the total number of 10 to 17-year-olds sentenced in 2007. In all regions of England more than 70 per cent of young offenders sentenced at magistrates' courts and the Crown Court received community sentences, except for North East (69 per cent). West Midlands had the highest rate at 78 per cent, with a two further regions above 75 per cent (South West and South East). London's percentage was equal to the England average of 74 per cent, while Wales' was 3 percentage points lower at 71 per cent.

\section{Conclusions}

This article has shown that there are many ways in which children's lives differ according to the part of the country and the type of area in which they live. At regional level it often appears that children and young people under the age of 20 in London and the northern regions (and sometimes the midlands) do less well than those in the rest of the southern regions.

Examples of this pattern are income deprivation, low birthweight and juvenile sentencing. In the South East and South West more than half of three- and four-year olds attend private or voluntary facilities rather than maintained school places. When it comes to children needing to go into local authority care, the lowest proportions are found in the South East and East Midlands.

When income deprivation is examined at sub-regional level in England it becomes clear that many of the differences in 
children's experiences at regional level are related to income deprivation, at least to some extent. When children from only the most deprived neighbourhoods are considered, educational achievement shows considerable variability between areas.

Analysis by income deprivation (IDACI) and the Rural and Urban Area Classification for England shows that many of the worst outcomes for children and young people are found in Urban areas (with total populations over 10,000). Taking the North East as an example, deprivation affects children most in Urban areas. The least deprived neighbourhoods are in suburban areas and small towns, while the most rural areas are neither most deprived nor least deprived.

Some variations appear London-centric. Children in London have a younger age-profile and are more likely to be from an ethnic minority than in other regions. This is partly because more children arrive into London from abroad than into other

\section{References}

General

'The United Nations Convention on the Rights of the Child', United Nations Children's Fund, available at: www.unicef.org/crc/

'Early Years Framework', The Scottish Government, available at: www.scotland.gov.uk/Topics/People/Young-People/Earlyyears-framework

Every Child Matters, HM Treasury (2003), available at: www.everychildmatters.gov.uk/_files/ 3EF03C6E29A6706656E18EF711A09158.pdf

Every Child Matters: Next Steps, Department for Children, Schools and Families (2004), available at: www. everychildmatters.gov.uk/_files/A39928055378AF27E9122D7 34BF10F74.pdf

The Children's Plan: Building Brighter Futures Department for Children, Schools and Families (2007), available at: www.dcsf.gov.uk/publications/childrensplan/downloads/The_ Childrens_Plan.pdf

The New Performance Framework for Local Authorities and Local Authority Partnerships: Single Set of National Indicators, Communities and Local Government (2007), available at: www.communities.gov.uk/publications/localgovernment/ nationalindicator

Public Service Agreements: The new performance management framework, HM Treasury (2007), available at: www.hm-treasury.gov.uk/pbr_csr07_psaindex.htm

National Performance Framework The Scottish Government (2009), available at: www.scotland.gov.uk/About/purposestratobjs regions and a proportion of children move out of London to the surrounding regions. London also has a high birth rate compared with other regions.

London and the South East have the lowest vaccination takeup rates for the main childhood immunisations, especially MMR. Conversely, there is a higher rate of conceptions among young women under 18 in the north of England than the south, but they are more likely to end in abortion in London and the South East.

Most importantly, the experiences of children in different neighbourhoods within the same region may differ much more according to other factors such as deprivation and rurality. Growing up in a low income family in one region will probably be more like one in deprived circumstances in another region than growing up in a more affluent neighbourhood in the same region.

\section{Child Poverty and Deprivation}

Measuring Child Poverty, Department for Work and Pensions (2003), available at: www.dwp.gov.uk/consultations/ consult/2003/childpov/final.asp

Child Poverty Review, HM Treasury (2004), available at: www.hm-treasury.gov.uk/spending_sr04_childpoverty.htm

'Poole's Children and Young People's Needs Analysis 2006/07', Poole Local Authority, (2007), available at: opinions.discussit.co.uk/research/ref:C48319EBF4DECF/ category:/

London Child Poverty Commission Launches Final Report Capital Gains, London Child Poverty Commission (2008), available at: 213.86.122.139/publications/capital-gains-0208. jsp

Households Below Average Income: An analysis of the income distribution 1994/95 - 2006/07, Department for Work and Pensions (2008), available at: www.dwp.gov.uk/asd/hbai/ hbai2007/pdf_files/full_hbai08.pdf

\section{Education and Training}

Raising The Participation Age - Four Building Blocks, Press Notice 2007/0198, Department for Children, Schools and Families (2007), available at: www.dcsf.gov.uk/pns/DisplayPN. cgi?pn_id=2007_0198

'Learning and Teaching Scotland, Curriculum for Excellence, Scotland's new curriculum', The Scottish Government, available at: www.Itscotland.org.uk/curriculumforexcellence/ index.asp

Health and Care

'People \& Society, Support for Children \& Families', The Scottish Government, available at: www.scotland.gov.uk/Topics/People/Young-People/childrenfamilies 
'Learning and Teaching Scotland, Looked After Children', The Scottish Government, available at: www.Itscotland.org.uk/ lookedafterchildren/index.asp

Cole T J (1997) 'Growth monitoring with the British 1990 growth reference', Arch Dis Child, 76, pp 47-49

Obesity among children under 11, National Centre for Research (2005), available at: www.dh.gov.uk/en/ Publicationsandstatistics/Publications/PublicationsStatistics/ DH_4109245

National Child Measurement Programme 2006/07 school year headline results, Department of Health (2008), available at: www.dh.gov.uk/en/Publichealth/Healthimprovement/ Healthyliving/DH_083093

National Child Measurement Programme: Detailed Analysis of the 2006/07 National Dataset, Department of Health (2008), available at: www.noo.org.uk/uploads/doc168_2_NOO_ NCMP_report230608.pdf

2008 Children and Young People's Well-being Monitor for Wales, Welsh Assembly Government (2008), available at: wales.gov.uk/topics/childrenyoungpeople/publications/ reports/2008wellbeingmonitor/?lang=en

Crime and Justice

Key facts and figures about the Criminal Justice System 2006/07, Criminal Justice Evidence and Analysis Unit, Office for Criminal Justice Reform (2007)

Sentencing Statistics, 2007 England and Wales Ministry of Justice Statistics bulletin, Ministry of Justice (2007), available at: www.justice.gov.uk/docs/sentencing-statistics-2007.pdf

Scottish Children's Reporter Administration 2007/08 Annual Report, Scottish Children's Reporter Administration (2008), available at: www.scra.gov.uk/publications/online_statistical_ service.cfm

Small area classifications, indices and statistics

'Urban and rural area definitions: a user guide', Communities and Local Government (2002), available at: www. communities.gov.uk/publications/planningandbuilding/ urbanrural

'Rural and Urban Area Classification, 2004' Office for National Statistics (2004), available at: www.statistics.gov.uk/geography/nrudp.asp
Report of the Inter-Departmental Urban-Rural Definition Group Statistical Classification and Delineation of Settlements February, 2005, Northern Ireland Statistics and Research Agency (2005), available at: www.nisra.gov.uk/geography/ default.asp10.htm

Northern Ireland Multiple Deprivation Measure 2005, Northern Ireland Statistics and Research Agency (2005), available at:http://www.nisra.gov.uk/aboutus/default.asp2. htm

Using the English Indices of Deprivation 2007: Guidance, Communities and Local Government (2007), available at: www.communities.gov.uk/documents/communities/ doc/615986.doc

The English Indices of Deprivation 2007, Communities and Local Government (2008): available at: www.communities. gov.uk/documents/communities/pdf/733520.pdf

Statistical Focus on Rural Wales, 2008, Welsh Assembly Government (2008), available at: wales.gov.uk/topics/ statistics/publications/focusrural08/?lang=en

Urban Rural Classification, 2007/2008, The Scottish Government (2008), available at: www.scotland.gov.uk/Publications/2008/07/29152642/0

Consultation on the proposed approach indicators for a Welsh Index of Multiple Deprivation: Child Index; 'Welsh Index of Multiple Deprivation (WIMD) Response to the consultation on the proposed approach and indicators for a WIMD: Child Index', Welsh Assembly Government, (2009), available at: wales.gov.uk/consultations/closedconsultations/statistics/ 2640581/?lang=en

Neighbourhood Statistics (England and Wales), Office for National Statistics, available at:

www.neighbourhood.statistics.gov.uk

Scottish Neighbourhood Statistics, The Scottish Government, available at:

www.sns.gov.uk

Northern Ireland Neighbourhood Statistics, Northern Ireland Statistics and Research Agency, available at: www.ninis.nisra.gov.uk 